\title{
A Study on the Impact Coefficient of Traffic Flows on a Large Cable-Stayed Bridge in a Windy Environment
}

\author{
L. Ma, ${ }^{1}$ D. J. Zhou, ${ }^{1}$ and W. S. Han ${ }^{2}$ \\ ${ }^{1}$ Department of Civil Engineering, University of Hohai, No.1 Xikang Road, Nanjing, Jiangsu 210098, China \\ ${ }^{2}$ Department of Bridge Engineering, University of Chang'an, Middle of S. 2nd Ring Road, Xian, Shaanxi 710064, China
}

Correspondence should be addressed to L. Ma; malinmalin8005@126.com

Received 26 June 2014; Accepted 28 August 2014; Published 17 November 2014

Academic Editor: Vadim V. Silberschmidt

Copyright (C) 2014 L. Ma et al. This is an open access article distributed under the Creative Commons Attribution License, which permits unrestricted use, distribution, and reproduction in any medium, provided the original work is properly cited.

\begin{abstract}
By developing a wind-vehicle-bridge coupling dynamic analysis system, the impact coefficient of traffic flows on a cable-stayed bridge and its probabilistic distribution are studied in the paper. Some important influence factors of the impact coefficient, such as the vehicle-bridge coupling effect, traveling velocity, and traffic density, are analyzed. The influence of the coupling effect between a bridge deck's buffeting and vehicles' vibration on the impact coefficient of traffic flows on a cable-stayed bridge is paid due attention to. The results show that vehicle-bridge coupling effect and surface roughness exert important influence on the impact effect of a cable-stayed bridge. Considering that impact coefficient of traffic flows on a bridge bears the characteristics of randomness, the paper, on the basis of a large number of samples, interprets the influence of traveling velocity and traffic density in view of its probabilistic distribution. In view of results derived from the coupling dynamic analysis, it is suggested that the impact coefficient be $25 \%$ for all spans of a long cable-stayed bridge like the Sutong Yangtze Bridge.
\end{abstract}

\section{Introduction}

The impact coefficient is an important problem in bridge design. Currently, the code provisions of impact coefficients in bridge design specifications could be classified into two categories: one gives the correlation between impact coefficients and bridges' lengths, while the other provides the correlation between impact coefficients and bridges' basic frequencies. Owing to the limitation of theoretical studies and calculating technology, many early studies on impact coefficients rely on field measurements. And on the basis of these measurements, code provisions were offered in design specifications. However, the measurements mainly concentrated on short or medium-length bridges. As we know, there are many factors such as driving velocity, bridge dynamic characteristics, and surface roughness, which will influence the impact effect of a bridge. A field measurement entails substantial human and financial resources. To study the impact coefficient problem of bridge components and so forth, bridge motion equations under the action of moving loads were developed into a vehicle-bridge coupling vibration analysis system.
The development of vehicle-bridge coupling vibration analysis technology has made it possible to study impact coefficients through numerical simulation. Such simulation could bring various influential factors into consideration and save both labor and financial resources. Previous studies [14] analyzed impact coefficients by using a vehicle-bridge coupling analysis system and considering the influence of surface roughness on impact coefficients.

But for a long cable-stayed bridge, some special features that do not exist in short-span bridges appear, such as simultaneous presence of various trucks and significant sensitivity to the wind. In recent years, there have been a number of studies on coupled wind-vehicle-bridge systems. For example, the studies on the coupled vibration between road vehicles and cable-stayed bridges in a cross wind environment could be found in the literature $[5,6]$. In addition, vehicle-bridge coupling analysis under the action of a highway stochastic traffic flow was paid more attention to. Au et al. [7] studied the bridge motion under a traffic flow, in which axle loads whose statistical characteristics accord with the real situations were applied to a bridge model, but vehicle vibration and coupling 
effect were neglected, and space intervals among vehicles were simplified into definite values.

A study on the impact coefficient of a large cablestayed bridge is conducted by a newly developed windvehicle-bridge coupling analysis system. Given that there are various types of vehicles in an actual traffic flow, the mathematic models of 4-axle, 5-axle, and 6-axle vehicles are deduced and incorporated into current wind-vehiclebridge coupling analysis system. Corresponding calculating programs are written in Fortran 90. With the Sutong Yangtze Bridge as an example, the impact effect of the bridge's three spans of different lengths is studied based on the developed wind-vehicle-bridge system. The differences between impact coefficients of traffic flows on the bridge and those of single vehicles on it are discussed. The coupling effect between vibrations of vehicles and the buffeting of the bridge is studied and impact coefficients of traffic loads on a cable-stayed bridge in a strong windy environment are paid due attention to. Impact coefficients from the coupling dynamical analysis in this paper are further compared with the results derived from bridge design specifications.

\section{Vehicle-Bridge Coupling Vibration Analysis System with a Traffic Flow and Wind Loads}

2.1. Dynamical Model of a Bridge. The analytical model of a long-span cable-stayed bridge is established through the finite element method (FEM) using different kinds of elements such as beam elements and link elements in this study. According to structural dynamics and finite element theory, the movement equation of a bridge model could be expressed as

$$
\mathbf{M}_{\mathbf{b}} \ddot{u}_{b}(t)+\mathbf{C}_{\mathbf{b}} \dot{u}_{b}(t)+\mathbf{K}_{\mathbf{b T}} u_{b}(t)=\mathbf{F}_{\mathbf{b}}(t),
$$

where $\mathbf{M}_{\mathbf{b}}, \mathbf{C}_{\mathbf{b}}, \mathbf{K}_{\mathrm{bT}}$ denote the mass matrix, the damping matrix, and the tangent stiffness matrix of a bridge, respectively. In this study, the material is homogeneous, isotropic, and linearly elastic. The Rayleigh damping matrix is adopted. $\mathbf{F}_{\mathbf{b}}(t)$ denotes equivalent node loads caused by external loads. With regard to the wind-vehicle-bridge coupling system, the bridge subsystem's equivalent loads include

$$
\mathbf{F}_{\mathbf{b}}(t)=\mathbf{F}_{\mathrm{bg}}+\mathbf{F}_{\mathrm{vb}}+\mathbf{F}_{\mathrm{stb}}+\mathbf{F}_{\mathrm{bub}}+\mathbf{F}_{\mathrm{seb}},
$$

where $\mathbf{F}_{\mathrm{bg}}, \mathbf{F}_{\mathrm{vb}}, \mathbf{F}_{\mathrm{stb}}, \mathbf{F}_{\mathrm{bub}}, \mathbf{F}_{\mathrm{seb}}$ denote self-weight, vehicle load, static wind load, buffeting force, and self-excited force, respectively.

A study on the impact coefficient of a cable-stayed bridge is conducted by taking the Sutong Yangtze Highway Bridge, a large cable-stayed bridge, as an example. The total length of the bridge is 8,206 meters $(26,923 \mathrm{ft})$. Its main channel is a cable-stayed bridge with a span of 1,088 meters $(3,570 \mathrm{ft})$ and had been with the longest cable-stayed bridge in the world until 2012. Its two side spans are 300 meters (980 ft) long each, and there are another four small cable spans (see Figure 1(a)). The bridge received the 2010 Outstanding Civil Engineering Achievement Award (OCEA) from the American Society of Civil Engineers. Two towers of the bridge are 300.4 meters
(986 ft) high and are the second tallest in the world until now. The tower is an inverted Y-shaped reinforced concrete structure with one connecting girder between the tower legs. From each tower, 34 stay cables radiate downwards in each of the four planes to support the bridge deck. The interval between every two cables is $16.2 \mathrm{~m}$ at the height of the bridge deck. The outer cable is up to 577 meters $(1,885 \mathrm{ft})$ and is the longest in the world. The plane view size of foundation of pile group is $113.75 \times 48.1$ square meters and is the largest globally. The bridge deck is a steel box girder with transverse and longitudinal internal diaphragms and has fairing noses on both sides. The total width of the bridge deck is 41 meters including the fairing noses (see Figure 1(b)). Six standard highway lanes in two directions are designed, the traveling velocity of navigation channels is designed at $100 \mathrm{~km} / \mathrm{h}$, and that of nonnavigation channels is designed at $120 \mathrm{~km} / \mathrm{h}$. In Figure 1, the points A, B, and C denote the mid-spans of the 2nd, 3rd, and 4th spans.

A three-dimensional finite element model is established for the main channel of the Sutong Yangtze Bridge. Compared with the bridge length, the bridge width of $41 \mathrm{~m}$ is still very narrow. The existence of various stiffening ribs inside the steel box can ensure that the applicability of the plane crosssection assumption is applicable and a three-dimensional beam element model can embody the main vibration modes of the whole bridge. On the basis of the plane cross-section assumption, the main girder model adopted in this paper is the backbone model. That is to say, the bending, torsion stiffness, and the mass of the girder are all concentrated over the middle line consisting of three-dimensional beam elements. Rigid cross-girders with no mass are used to realize force transmission between the cables and the main girder. The two bridge towers are also discretized by using threedimensional beam elements. The sag effect of inclined cables exerts nonignorable influence on the cable stiffness, which is considered by equivalent elastic modulus in this paper. The simplification will not influence the dynamic characteristics of the whole bridge and thus will not influence the response of the bridge deck. Fixed constraints are adopted at the bottom of piers and towers. Vertical and lateral coupling constraints are used at the joints of the piers and the main beam. Since the bridge is a longitudinal floating structural system, only vertical coupling constraints are adopted at the joints of the towers and the main beam. The influence of the bridge deck pavement on dynamic characteristics is included by using lumped masses. The total finite element model contains 866 nodes, 1122 elements, 16 supporting conditions, 28 coupling constraints, and 636 sections. Some modes and corresponding natural frequencies of the bridge are given in Table 1 . The 3rd-4th modes are the first two vertical bending modes that mainly present the main span's bending while the first two vertical modes embodying side spans' bending are the 47th48th modes. Figure 2 shows the FE model of the bridge and some important vertical bending modes. In the dynamical analysis, the damping ratio of the bridge is assigned at $0.5 \%$.

2.2. Dynamical Models of Multiaxle Road Vehicles. According to the literature [8], nationwide surveys have been conducted in China and data of almost 70,000 vehicles have been 


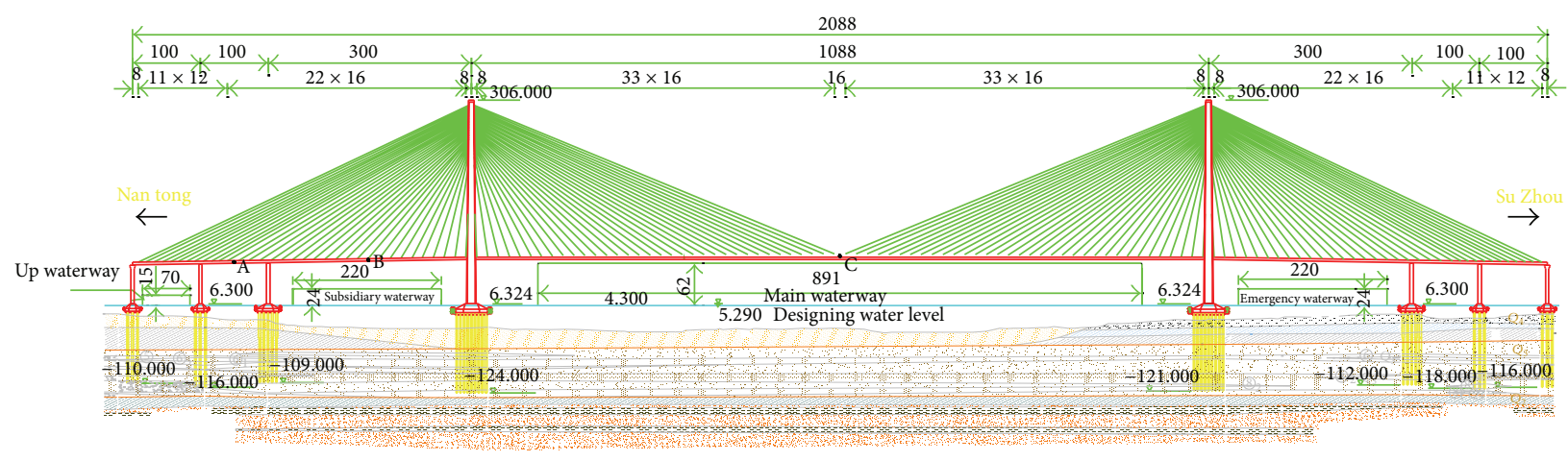

(a)

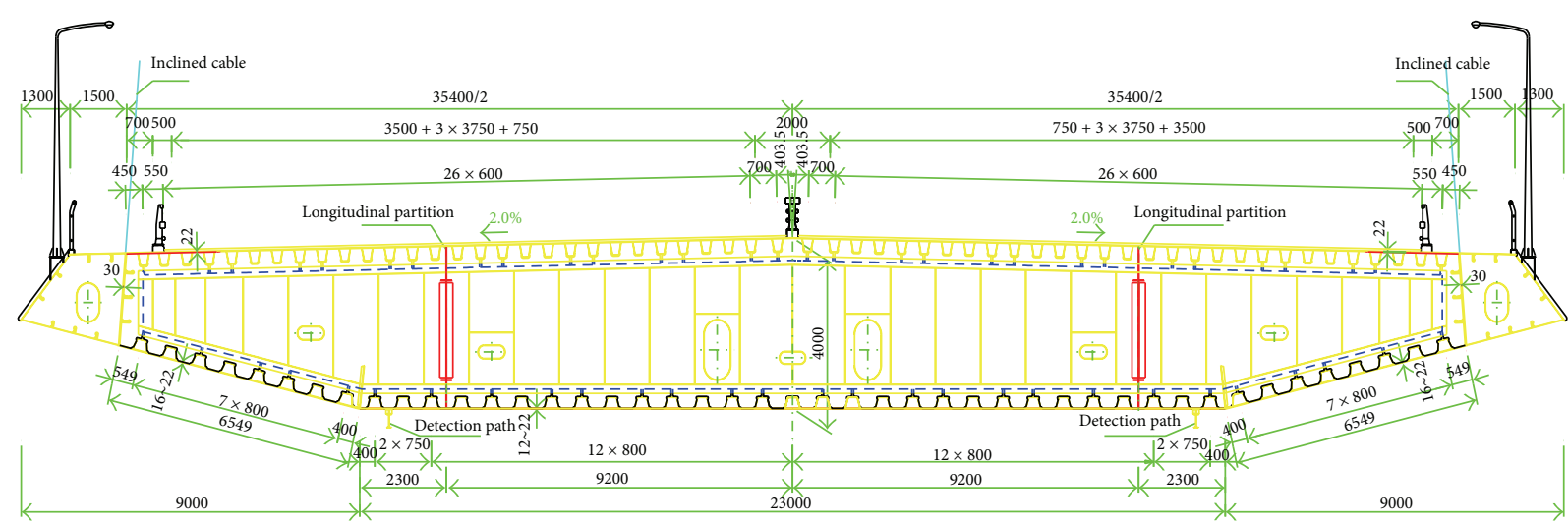

(b)

FIgURE 1: Layout of the Sutong Yangtze Bridge: (a) longitudinal layout (unit: m); (b) cross-section (unit: mm).

TABle 1: Frequencies and modes of the Sutong Yangtze Bridge.

\begin{tabular}{lcc}
\hline Mode order & Mode description & Frequency $(\mathrm{Hz})$ \\
\hline 1 & Longitudinal floatation & 0.06 \\
2 & Symmetric lateral bending & 0.10 \\
3 & Symmetric vertical bending & 0.18 \\
4 & Antisymmetric vertical bending & 0.22 \\
5 & Antisymmetric lateral bending & 0.27 \\
6 & Symmetric vertical bending & 0.30 \\
$\vdots$ & $\vdots$ & $\vdots$ \\
47 & Antisymmetric vertical bending & 0.97 \\
48 & Symmetric vertical bending & 1.03 \\
\hline
\end{tabular}

collected. The vehicles were classified according to axle numbers and types. The weighted average of axles' weights and intervals between axles were calculated, and the typical vehicle types were obtained, which are shown in Table 2 . This paper focuses on the impact effect of vehicles on a large bridge. Since vehicles' vibration and vehicle-bridge coupling effect play an important role in impact effect in certain cases, vehicles' dynamical characteristics should be taken into consideration. In most researches on vehicle-bridge mutual dynamical action, a vehicle is taken as consisting of several rigid bodies that are connected by springs and dampers. The springs are generally deemed as linear, and dampers are viscous. Suppose a vehicle moves at a constant speed along a line; thus the longitudinal vibration could be neglected. In previous vehicle-bridge coupling vibration analysis systems, vehicle types mainly consist of 2- and 3-axle vehicles; but quantities of multiaxle vehicles exist in real highway traffic flow. Here, the dynamical model of a 4-axle vehicle model is shown in Figure 3, as an example. A vehicle body has five freedom degrees: vertical movement $Z_{V}$, lateral movement $Y_{V}$, rolling movement $\phi_{V}$ (about $X$ coordinate), nodding movement $\theta_{V}$ (about $Y$ coordinate), and yawing movement $\varphi_{V}$ (about $Z$ coordinate). Each wheel has two freedom degrees: lateral movement $Y_{s i}(i=1,2, \ldots, 2 n, n$ denote the number of axles) and vertical movement $Z_{s i}(i=1,2, \ldots, 2 n)$. In Figure 3, $K_{u z i}, C_{u z i}, K_{u y j}$, and $C_{u y j}(i=1, \ldots, 8)$ denote 


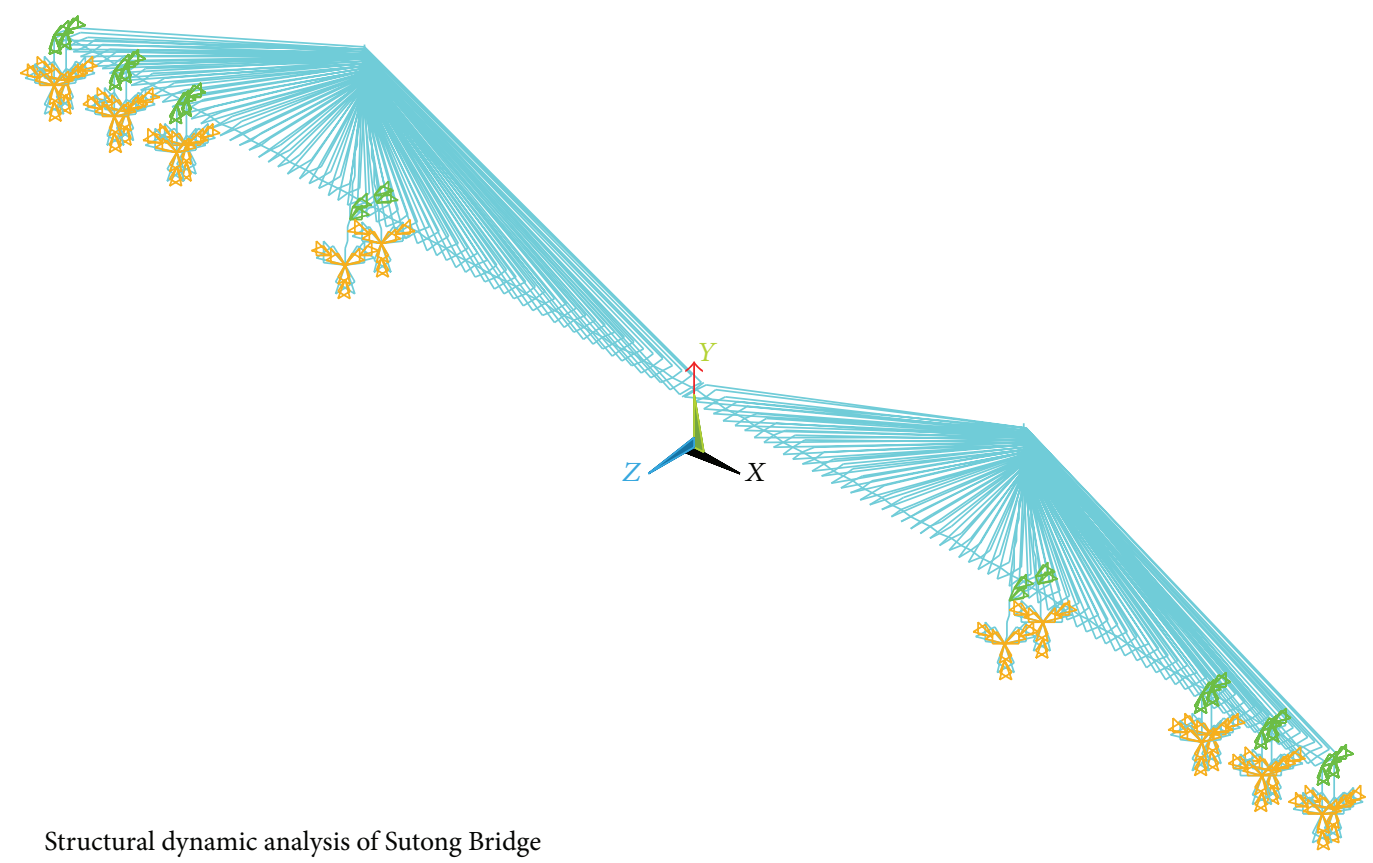

(a)
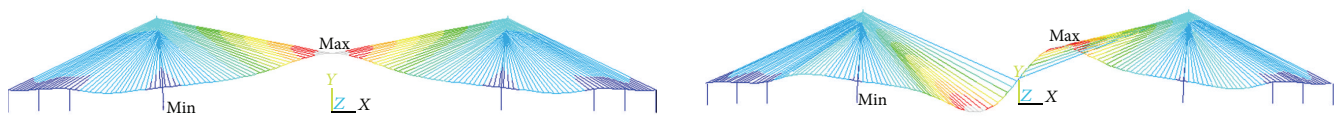

\begin{tabular}{|c|c|c|c|c|c|c|c|}
\hline 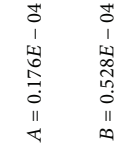 & $\begin{array}{l}\text { tr } \\
1 \\
1 \\
101 \\
\infty \\
\infty \\
0 \\
0 \\
11 \\
0\end{array}$ & 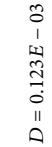 & 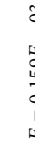 & & 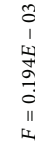 & & \\
\hline
\end{tabular}

Dynamical analysis of Sutong Bridge

(b)

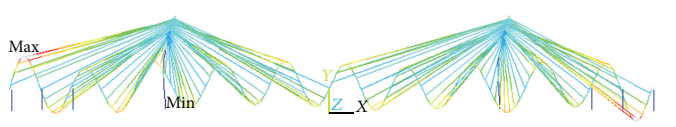

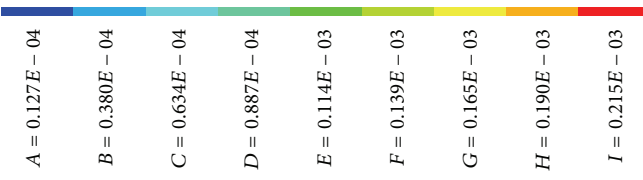

Dynamical analysis of Sutong Bridge

(d)

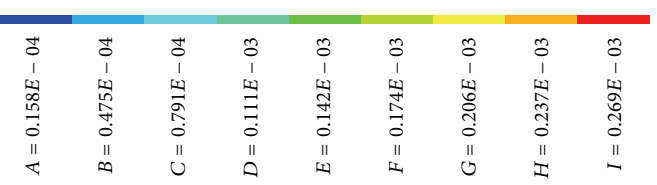

Dynamical analysis of Sutong Bridge

(c)

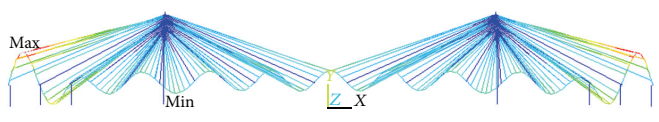

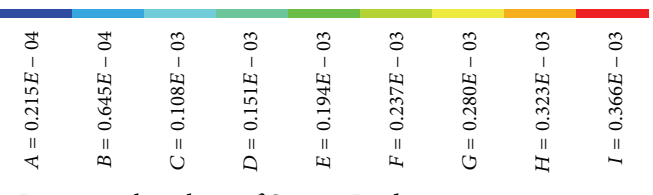

Dynamical analysis of Sutong Bridge

(e)

FIGURE 2: FE model of the bridge and its vertical bending modes: (a) FE model; (b) the 3rd mode; (c) the 4th mode; (d) the 47th mode; (e) the 48 th mode.

the rigidity and damping of the upper suspension system of the vehicle in vertical and lateral directions, respectively; $L_{i}(i=1, \ldots, 4)$ denotes the horizontal distance of the $i$ th axle from the center of gravity of the vehicle body; $b_{1}$ denotes half of the transverse distance between tires; $h_{v}$ denotes the vertical distance of the center of gravity of the vehicle body from the ground. The dynamics equation of the vehicle models could be deduced by the Lagrange principle, which is expressed in the following form:

$$
\mathbf{M}_{\mathrm{v}} \ddot{\mathbf{u}}_{\mathrm{v}}+\mathrm{C}_{\mathrm{v}} \dot{\mathbf{u}}_{\mathrm{v}}+\mathbf{K}_{\mathrm{v}} \mathbf{u}_{\mathrm{v}}=\mathrm{F}_{\mathrm{stv}}+\mathrm{F}_{\mathrm{buv}}+\mathrm{F}_{\mathrm{bv}},
$$

where $\mathbf{u}_{v}$ is vector of vehicle displacement; $\mathbf{M}_{v}, \mathbf{C}_{v}, \mathbf{K}_{v}$ are mass matrix, damping matrix, and stiffness matrix of the vehicle, respectively; $\mathbf{F}_{\text {stv }}, \mathbf{F}_{\text {buv }}$ are static wind loads and 
TABLE 2: Typical style for vehicle loads.

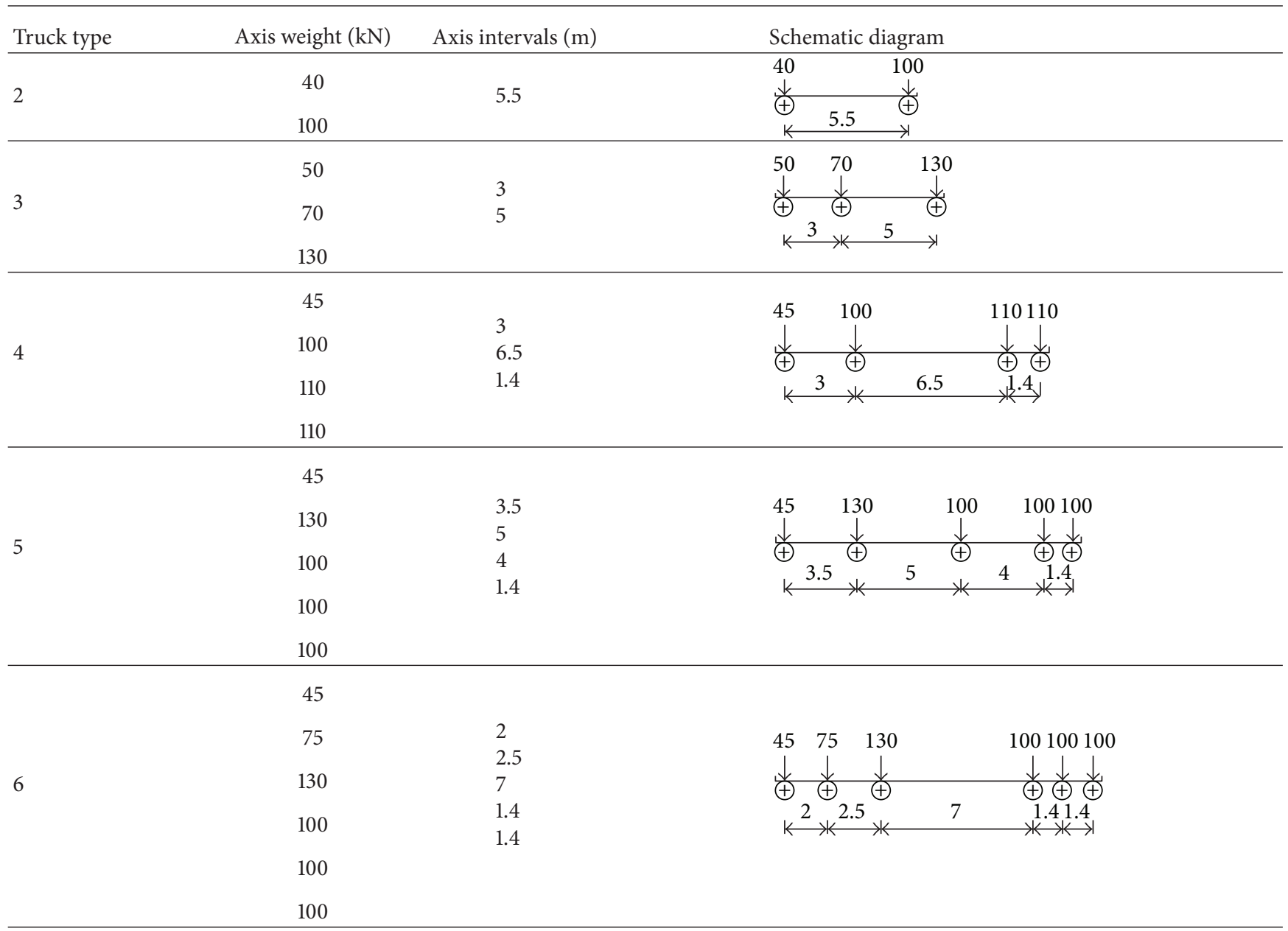

buffeting loads, respectively; $\mathbf{F}_{\mathbf{b v}}$ is tire-deck interactions which are induced by deck roughness and deck motion. The dynamical parameters of vehicle models, such as stiffness and damping, are given in Table 3, which are available in the literature [5].

2.3. Calculation Method of Vehicle-Bridge Coupling System. It is assumed that the surface roughness of a bridge deck is not that rough to make a vehicle jump from the deck's surface and that there is no lateral sliding between the vehicle and the bridge deck; thus all tires of the vehicle always remain in contact with the bridge deck. The movement of a bridge deck produces additional roughness, which makes the vehicle vibration couple with the bridge deck's movement. A separate iteration method is used to solve the vehicle-bridge coupling system in this paper. Dynamical equations for each vehicle and the bridge are solved individually, and the consistent geometry relationship between the vehicles and the bridge is satisfied by repeatedly solving the two subsystems. The specific procedures are as follows.

(1) Combine surface roughness and the movements of the bridge deck at the last time step and calculate the forces acting on vehicles running on the bridge deck.
(2) Solve individually the vehicle subsystem using Newmark integration method to obtain the initial vehicle response $\left(\ddot{u}_{v}^{t}, \dot{u}_{v}^{t}, u_{v}^{t}\right)$ at current time step.

(3) Calculate the static wind forces, buffeting forces, and self-excited forces acting on the bridge deck according to the movement state of the bridge deck $\left(\ddot{u}_{b}^{t-1}, \dot{u}_{b}^{t-1}\right.$, $\left.u_{b}^{t-1}\right)$ at the last time step, and solve individually the bridge subsystem and obtain the responses of the bridge $\left(\ddot{u}_{b}^{t}, \dot{u}_{b}^{t}, u_{b}^{t}\right)$ at the current time step.

(4) The movements of the bridge deck obtained in step (3) are applied to step (1). Then steps (1) to (4) are repeated until the conditions of geometric compatibility at contact points are well satisfied and then the calculations for next time step continue.

The aforementioned analysis process is programmed using Fortran 90, in which two self-defined structural data types are used to describe dynamical models and motion state of vehicles, respectively. All the data of the bridge model, vehicle models, traffic flow, surface roughness, turbulent wind, and so forth are saved in text files and read by programs.

In order to verify the precision of the separate iteration method, which is used for the dynamical analysis of the 


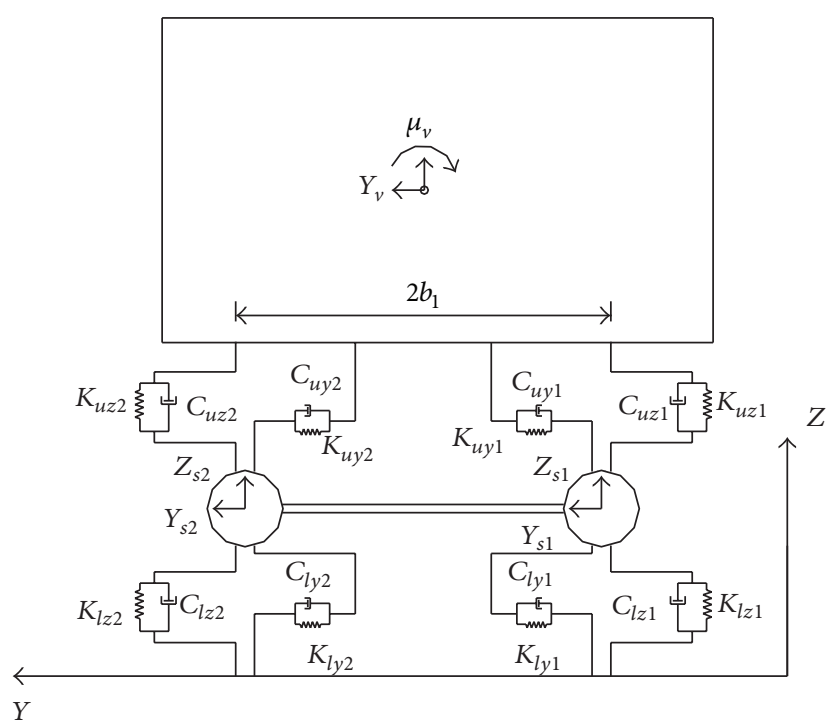

(a)

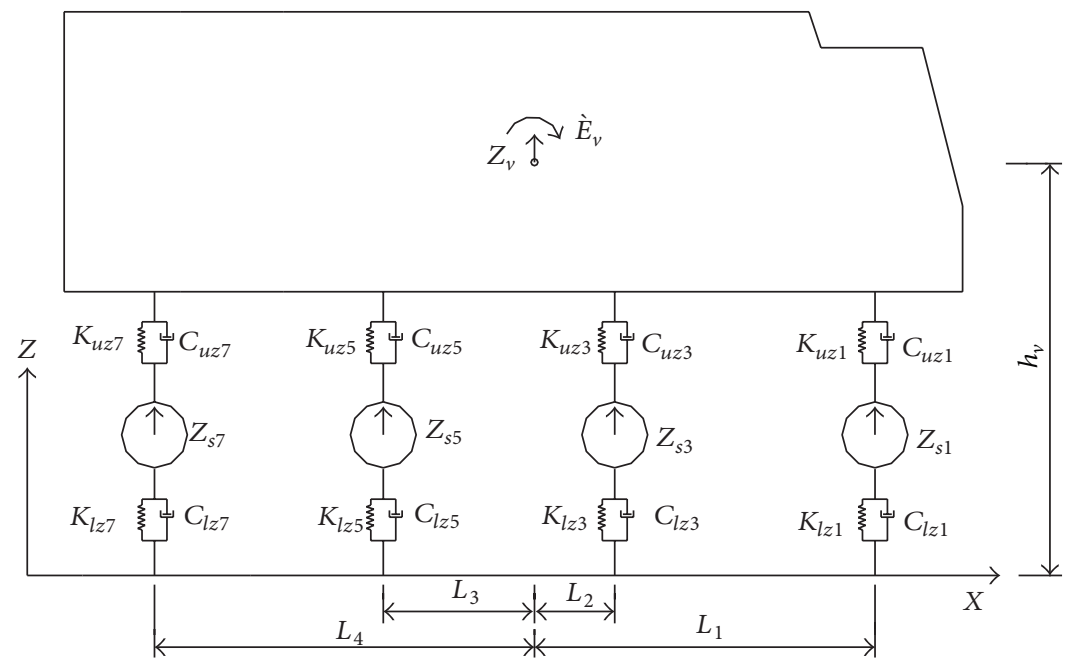

(b)

FIgURe 3: Dynamic models of a 4-axle vehicle: (a) cross-section view; (b) elevation view.

TABLE 3: Major parameters of vehicles used in case study.

\begin{tabular}{lcc}
\hline Parameter & Value & Unit \\
\hline Upper vertical spring stiffness $\left(K_{u z i}, i=1,2, \ldots, 2 n\right)$ & 399 & $\mathrm{kN} / \mathrm{m}$ \\
Upper lateral spring stiffness $\left(K_{u y j}, i=1,2, \ldots, 2 n\right)$ & 299 & $\mathrm{kN} / \mathrm{m}$ \\
Upper vertical damper damping coefficient $\left(C_{u z i}, i=1,2, \ldots, 2 n\right)$ & 23.21 & $\mathrm{kN} * \mathrm{~s} / \mathrm{m}$ \\
Upper lateral damper damping coefficient $\left(C_{u y j}, i=1,2, \ldots, 2 n\right)$ & 5.18 & $\mathrm{kN} * \mathrm{~s} / \mathrm{m}$ \\
Lower vertical spring stiffness $\left(K_{l z i}, i=1, \ldots, 2 n\right)$ & 351 & $\mathrm{kN} / \mathrm{m}$ \\
Lower lateral spring stiffness $\left(K_{l z i}, i=1, \ldots, 2 n\right)$ & $\mathrm{kN} / \mathrm{m}$ \\
Lower vertical damper damping coefficient $\left(C_{l z i}, i=1, \ldots, 2 n\right)$ & 0.8 \\
Lower lateral damper damping coefficient $\left(C_{l z i}, i=1, \ldots, 2 n\right)$ & 0.8 \\
Mass of wheel sets $\left(M_{s i}, i=1, \ldots, 2 n\right)$ & $\mathrm{kN} * \mathrm{~s} / \mathrm{m}$ \\
Frontal area of the vehicle $\left(A_{f}\right)$ & $\mathrm{kN} / \mathrm{m}$ \\
Height of the centre of gravity of the vehicle body above the surface of the road or the bridge deck $\left(h_{V}\right)$ & 10.5 & $\mathrm{~kg}$ \\
\end{tabular}


vehicle-bridge coupling system in this paper, the responses of a simple-supported beam subjected to a moving mass and a moving sprung mass are calculated, respectively. The simple beam is $30 \mathrm{~m}$ long. Its modulus of elasticity and geometrical moment of inertia are $3.45 E+10$ and $10 \mathrm{~m}^{4}$, respectively. The moving mass weighs 30 tons and stiffness of spring is $399 \times 4 \mathrm{KN} / \mathrm{m}$. The moving velocity of the mass or the sprung mass is assigned the value of $10 \mathrm{~m} / \mathrm{s}$. The damping of the beam and surface roughness on the beam are not included in this example. Biggs [9] gave the motion equations for the vibration of the coupling system of a simple beam subjected to a moving sprung mass on the basis of modal analysis method. The matrix forms of the motion equations are as follows:

$$
\begin{aligned}
& {\left[\begin{array}{ccccc}
1 & m_{12} & \ldots & m_{1 N} & 0 \\
m_{21} & 1 & \ldots & m_{2 N} & 0 \\
\vdots & \vdots & \vdots & \vdots & \vdots \\
m_{N 1} & m_{N 2} & \ldots & 1 & 0 \\
0 & 0 & \ldots & 0 & M_{v s}
\end{array}\right]\left\{\begin{array}{c}
\ddot{q}_{1}(t) \\
\ddot{q}_{2}(t) \\
\vdots \\
\ddot{q}_{N}(t) \\
\ddot{z}_{v s}(t)
\end{array}\right\}} \\
& +\left[\begin{array}{ccccc}
\omega_{1}^{2} & k_{12} & \ldots & k_{1 N} & k_{1(N+1)} \\
k_{21} & \omega_{2}^{2} & \ldots & k_{2 N} & k_{2(N+1)} \\
\vdots & \vdots & \vdots & \vdots & \vdots \\
k_{N 1} & k_{N 2} & \ldots & \omega_{N}^{2} & k_{N(N+1)} \\
k_{(N+1) 1} & k_{(N+1) 2} & \ldots & k_{(N+1) N} & k_{v}
\end{array}\right]\left\{\begin{array}{c}
q_{1}(t) \\
q_{2}(t) \\
\vdots \\
q_{N}(t) \\
z_{v s}(t)
\end{array}\right\}
\end{aligned}
$$$$
=\left\{\begin{array}{c}
F_{G 1} \\
F_{G 2} \\
\vdots \\
F_{G N} \\
0
\end{array}\right\} \text {, }
$$

$$
\begin{gathered}
m_{n i}=\frac{2 M_{v u}}{m l} \sin \frac{n \pi v t}{l} \sin \frac{i \pi v t}{l}, \\
k_{n i}=\frac{2 k_{v}}{m l} \sin \frac{n \pi v t}{l} \sin \frac{i \pi v t}{l}, \quad(n, i=1,2, \ldots, N), \\
k_{n(N+1)}=k_{(N+1) n}=-\frac{2 k_{v}}{m l} \sin \frac{n \pi v t}{l}, \\
F_{G n}=\frac{2\left(M_{v s}+M_{v u}\right)}{m l} g, \quad(n=1,2, \ldots, N),
\end{gathered}
$$

where $q_{n}(t)$ denotes the $n$th generalized degree of freedom, $\omega_{n}$ denotes the $n$th frequency of the simple beam, and $\sin (n \pi v t / l)$ is its corresponding modal function; $N$ denotes the number of the used modal functions; $M_{v s}$ and $M_{v u}$ denote sprung mass and unsprung mass, respectively; $K_{v}$ denotes stiffness of spring; $v$ denotes moving velocity. When $M_{v s}$ and $K_{v}$ are set to zero, the responses of the simple beam subjected to a moving mass could be obtained. When $M_{v s}$ is set to zero, the responses subjected to a moving sprung mass in this example would be obtained. The vertical displacement and moment are calculated as follows:

$$
\begin{aligned}
z_{b}(x, t) & =\sum_{n=1}^{N} q_{n}(t) \sin \frac{n \pi x}{l}, \\
M((x, t)) & =-\sum_{n=1}^{N} q_{n}(t)\left(\frac{n \pi}{l}\right)^{2} \sin \frac{n \pi x}{l} .
\end{aligned}
$$

Figures 4(a)-4(d) give the responses of the simple beam subjected to a moving constant load, a moving mass, and a moving sprung mass, respectively. The figures show that the displacement and moment responses of the simple beam at mid-span obtained by the calculation programs in this paper are in accordance with those obtained by the method in the literature [9]. The first 10 modals are included in the calculation.

2.4. Wind Forces on the Sutong Yangtze Bridge. The bridge deck is a blunt body section, and the aerodynamic force it experiences is complicated. The three major parts of the wind force acting on a bridge deck, namely, the steady-state forces due to mean wind, buffeting forces due to wind turbulence, and wind-excited forces due to the aeroelastic interaction between bridge motion and fluent field, are included in the dynamical analysis in this paper. Generally speaking, the aerodynamic forces of cables are not comparative with those experienced by the bridge deck, and the cables' vibration exerts little influence on the bridge deck. Thus, like analyses of a bridge deck's vibration in most relevant literature, the aerodynamic forces of cables are ignored in this paper. The Sutong Yangtze Bridge is so famous that its aerodynamic force coefficients and flutter derivatives of the bridge deck are available in some published literatures. As we know, Reynolds number effect will influence aerodynamic force coefficients evidently. Here, the measured aerodynamic force coefficients of the Sutong Yangtze Bridge on the condition of high Reynolds number $\left(1.0 \times 10^{6} \sim 1.38 \times 10^{6}\right)$ in the literature [10] are adopted. The flutter derivatives of the bridge come from the literature [11].

2.5. Simulation of Surface Roughness on the Bridge Deck. As we know, surface roughness is generally regarded as a Gaussian stationary stochastic process. Simulation technology of surface roughness has been developed by some previous studies $[12,13]$. The power spectral density (PSD) functions, which were developed by Dodds and Robson [12] to describe the road surface roughness, are as follows:

$$
\begin{aligned}
& S(\phi)=A\left(\frac{\phi}{\phi_{0}}\right)^{-w 2}, \quad \phi \geq \phi_{0}, \\
& S(\phi)=A\left(\frac{\phi}{\phi_{0}}\right)^{-w 1}, \quad \phi \leq \phi_{0},
\end{aligned}
$$

where $A$ is roughness coefficient $\left(\mathrm{m}^{3} /\right.$ cycle $), \phi$ denotes space frequency, namely, wave number (cycle/m), $\phi_{0}$ denotes discontinuity frequency $(1 / 2 \pi)\left(\right.$ cycle/m), and $w_{1}, w_{2}$ are 


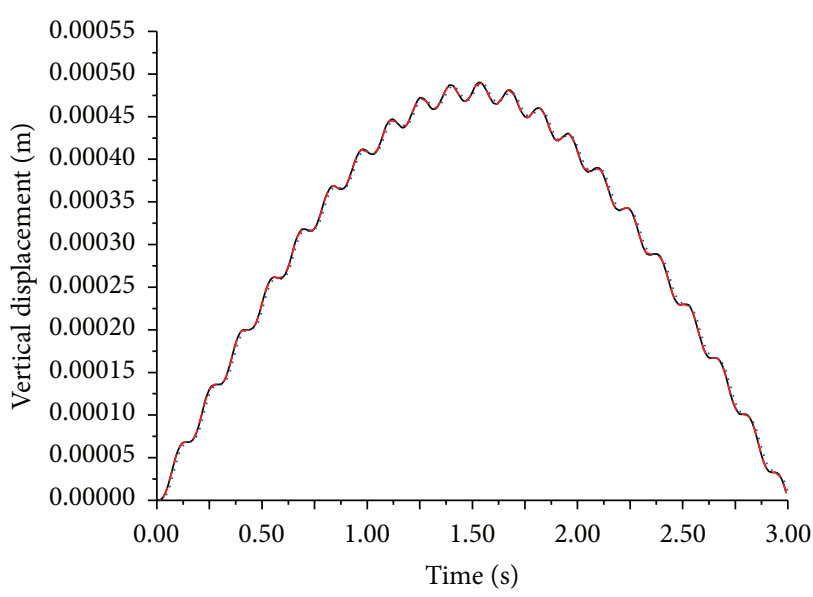

— Method adopted by this paper $\quad$ …... Result from Ansys 10.0 - - - Method put forward by Biggs

(a)

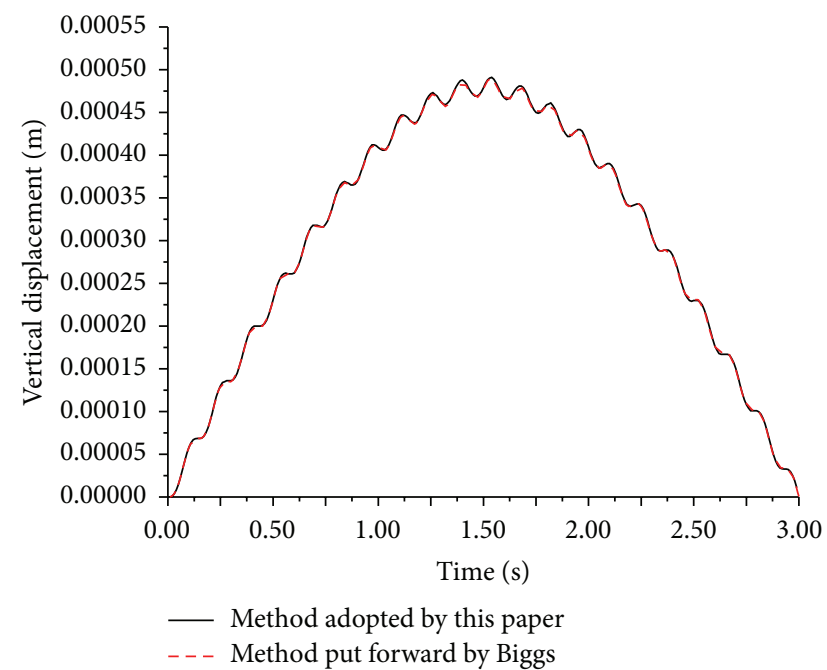

(c)

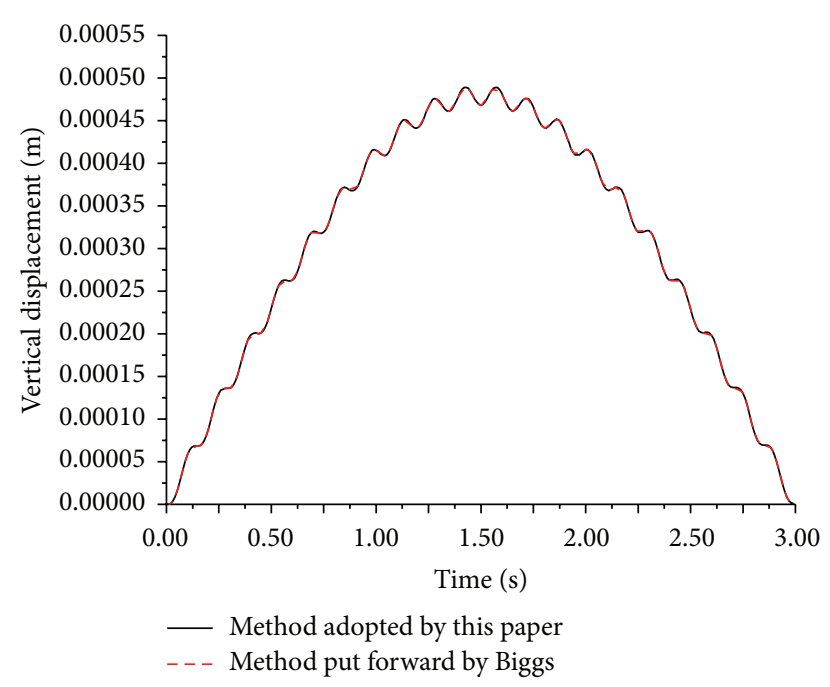

(b)

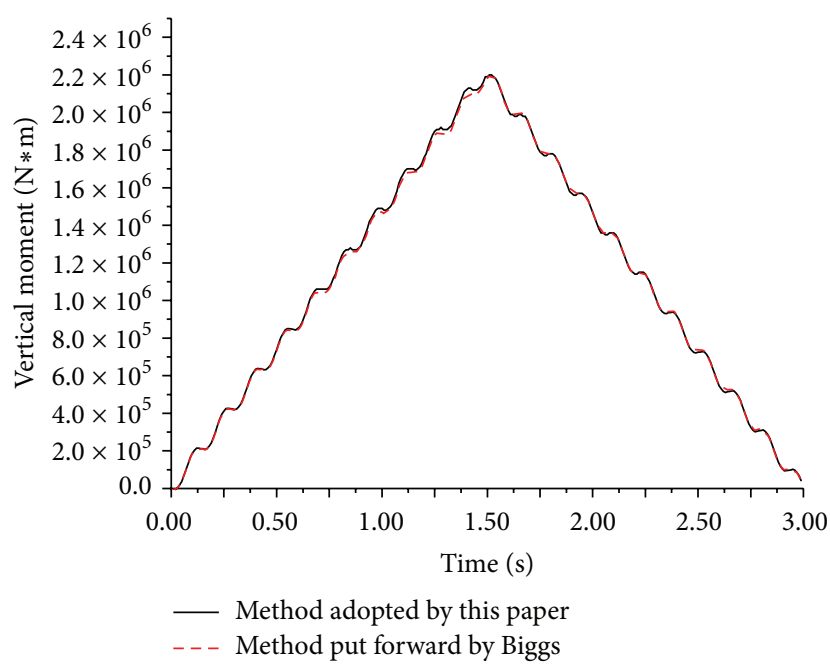

(d)

FIGURE 4: Dynamic response of a simply supported beam at mid-span: (a) vertical displacement under the action of a moving constant load; (b) vertical displacement under the action of a moving mass; (c) vertical displacement under the action of a moving sprung mass; (d) vertical moment under the action of a moving sprung mass.

roughness exponents. There are three different classes of roads, and each class has either two, three, or four road conditions, namely, very good, good, average, and poor. The values of roughness coefficient $A$ and exponents $w_{1}$ and $w_{2}$ are dependant on the class of road roughness, which were given in the literature [12]. Here, the class of surface roughness is supposed to be "good" or "average" of "Principal roads." The roughness coefficient $A$ equals $16 \times 10^{-6}$ or $64 \times$ $10^{-6} \mathrm{~m}^{3} /$ cycle, respectively. The exponents $w_{1}$ and $w_{2}$ are set to 2 to simplify the problem.

The minimum value of frequency for vehicle vibration is $0.5 \mathrm{~Hz}$ while the maximum is $30 \mathrm{~Hz}$; the lower limit of traveling velocity is supposed to be $0.5 \mathrm{~m} / \mathrm{s}$ and the upper limit is $35 \mathrm{~m} / \mathrm{s}$; the lower limit of space frequency of roughness is $0.5 / 35=0.014$ cycle $/ \mathrm{m}$ and the upper limit is $30 / 0.5=$ $60 \mathrm{cycle} / \mathrm{m}$. Longitudinal intervals are assigned at $0.1667 \mathrm{~m}$. Considering that surface roughness on a road or a bridge deck varies along the width of the bridge, multipath roughness is simulated. Each path roughness represents a roughness at a point along the bridge width. The simulated roughness and their PSD (power spectral density) are shown in Figures 5 and 6 . The simulated spectra are well accordant with their target spectra. A simulated roughness is periodic and the roughness only in one period is given in Figure 5. Since the bridge deck of the Sutong Yangtze Bridge is 2088 meters long, which is longer than the length of surface roughness in one period, the simulated roughness needs to be expanded according to its periodicity. 


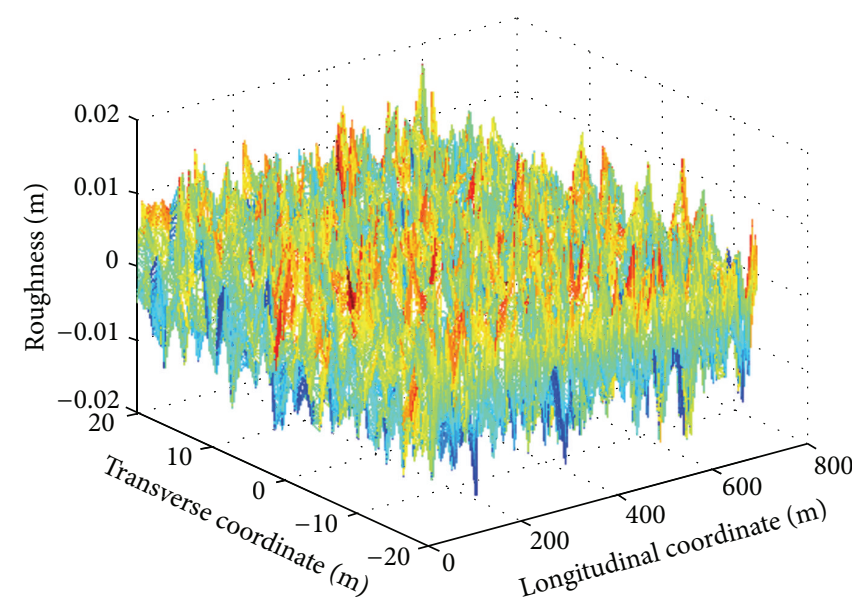

(a)

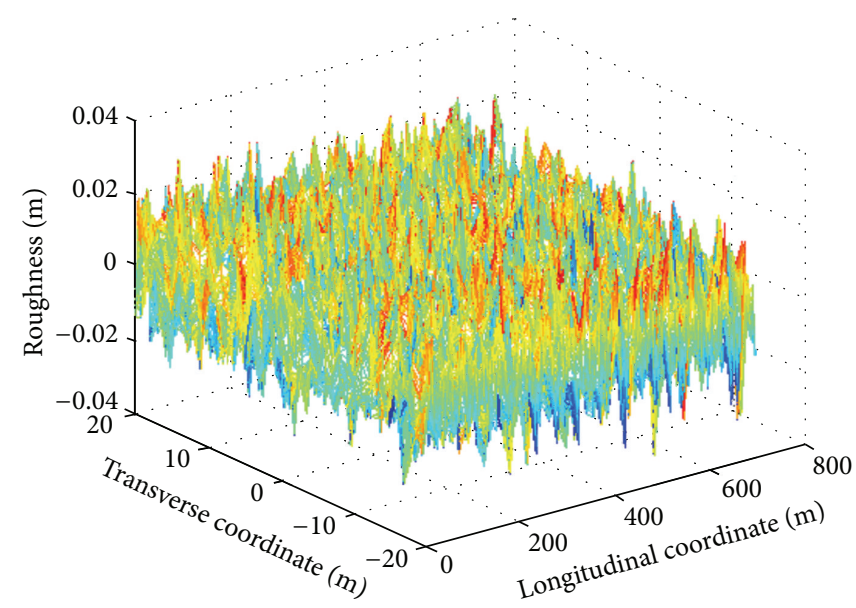

(b)

FIGURE 5: Multipath surface roughness: grade of roughness: (a) good; (b) average.

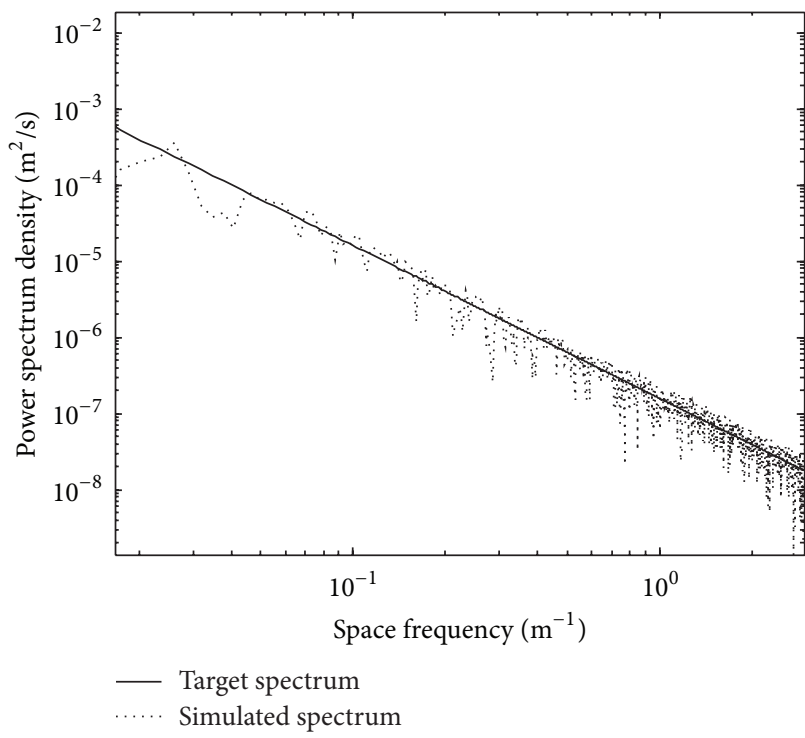

(a)

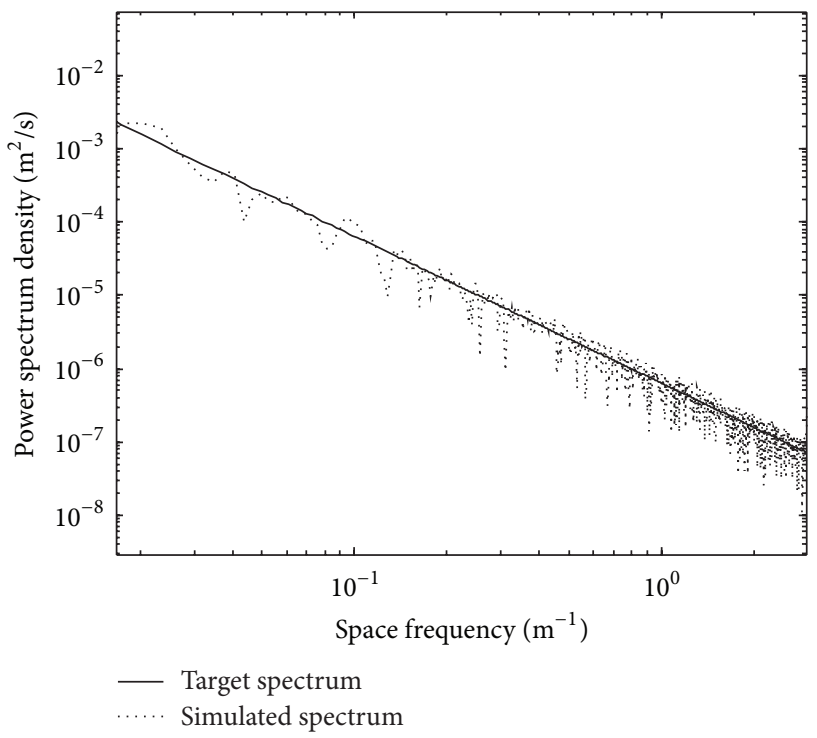

(b)

FIGURE 6: The power spectrum densities of surface roughness: grade of roughness: (a) good; (b) average.

\section{Impact Coefficient of a Large Cable-Stayed Bridge}

3.1. Vehicle-Bridge Coupling Vibration Analysis. Suppose a vehicle runs on the inner lane and its traveling velocity is $100 \mathrm{~km} / \mathrm{h}$. The grade of surface roughness on the bridge deck is supposed to be "average." Time histories of vehiclebridge coupling dynamic responses of the Sutong Yangtze Bridge under the action of single vehicles are given in Figures $7(\mathrm{a})-7(\mathrm{j})$, in which the static responses are obtained by neglecting all dynamic effect and surface roughness and dynamic responses are obtained by regarding all axles as moving constant loads. Point A represents the mid-span of a 100-meter-long span and point $C$ represents the midspan of the 1088-meter-long span, which will be referred to as the $1000 \mathrm{~m}$ span in the following context. Every axle is supported by two tires on the bridge deck and the contacting force of every tire fluctuates around half of its axle load. The contacting forces of the two tires of the same axle are somewhat different because the multipath surface roughness on the bridge deck is adopted.

The ratio of the maximum dynamic response to the maximum static one is the dynamic magnification coefficient $(1+I)$ and $I$ is the impact coefficient. Under the action of single vehicles, vertical displacements of the 1000-meterlong span are much larger than those of the 100-meter-long span. However, the former's impact coefficients are smaller than those of the latter. The surface roughness and vehicles' vibration make some contribution to impact coefficients of single vehicles on the $100 \mathrm{~m}$ span. Impact coefficients of 


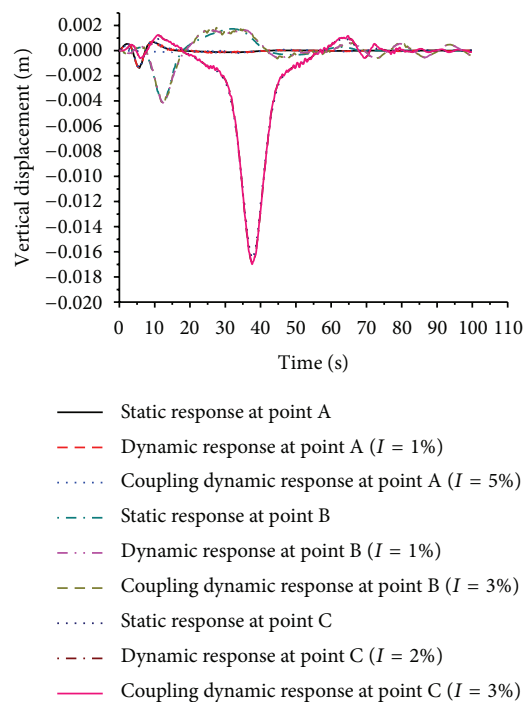

(a)

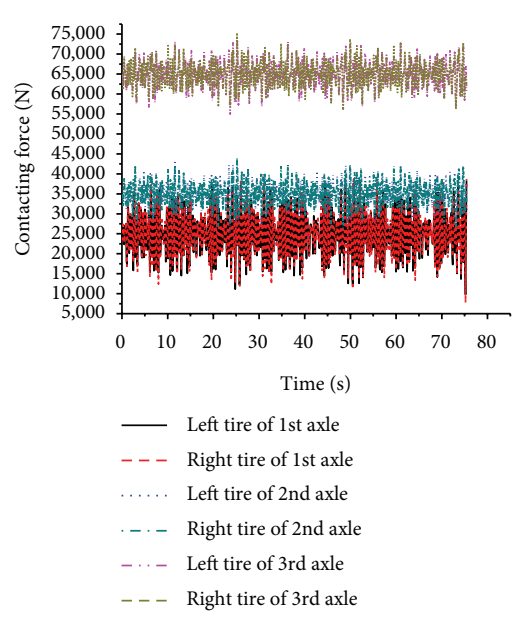

(d)

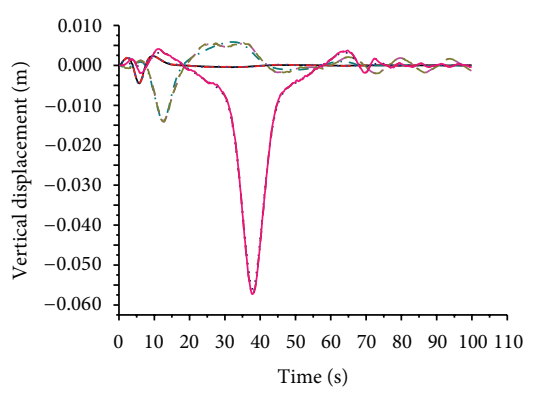

— Static response at point A

- - - Dynamic response at point A $(I=2 \%)$

..... Coupling dynamic response at point A $(I=2 \%)$

... - Static response at point B

-..- Dynamic response at point B $(I=1 \%)$

- - - Coupling dynamic response at point B $(I=2 \%)$

...... Static response at point $\mathrm{C}$

. . . - Dynamic response at point C $(I=2 \%)$

Coupling dynamic response at point C $(I=2 \%)$

(g)
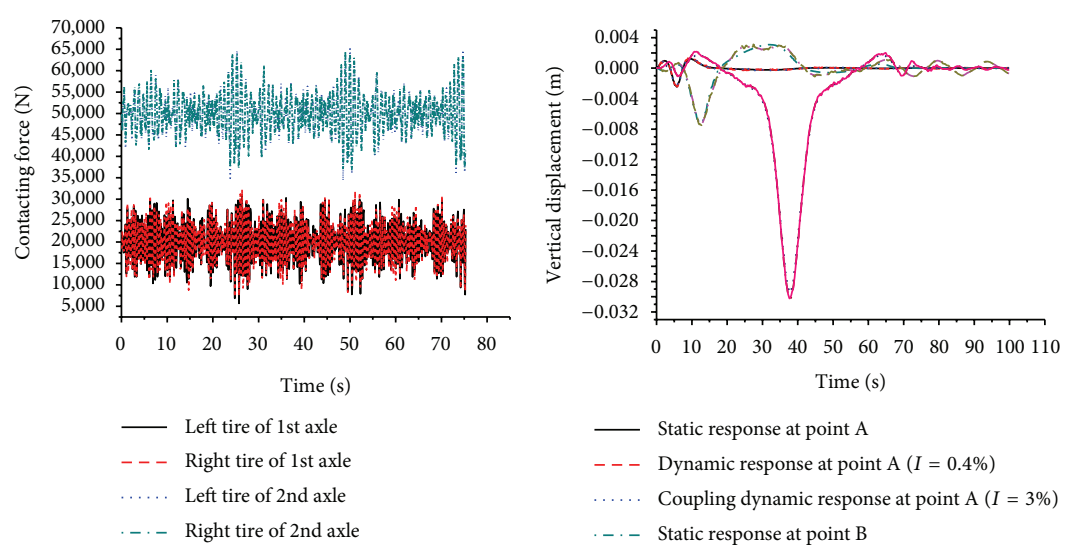

(b)
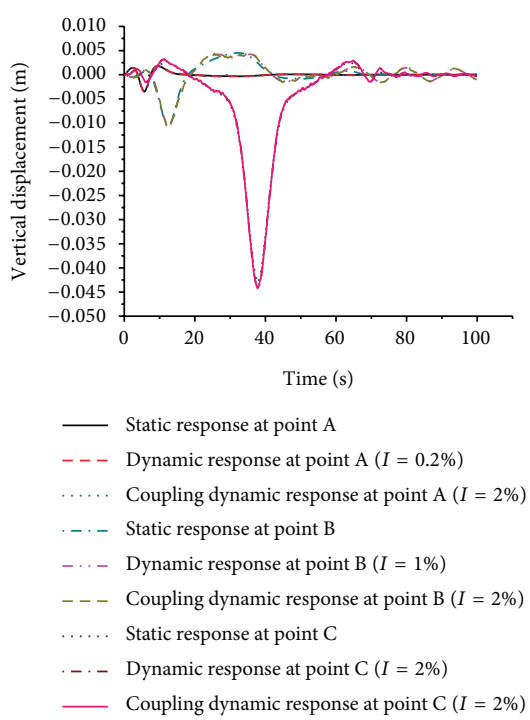

(e)
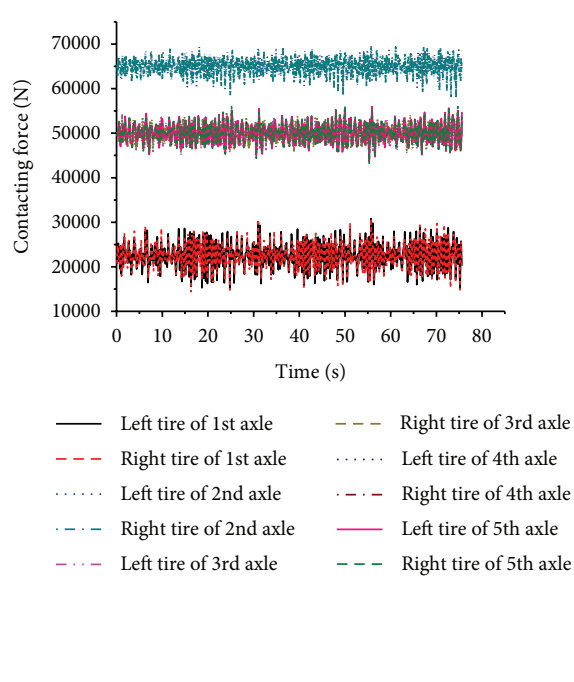

(h)

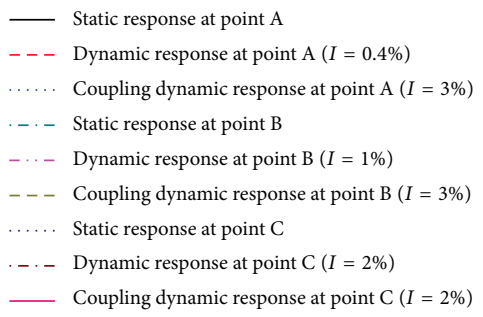

(c)

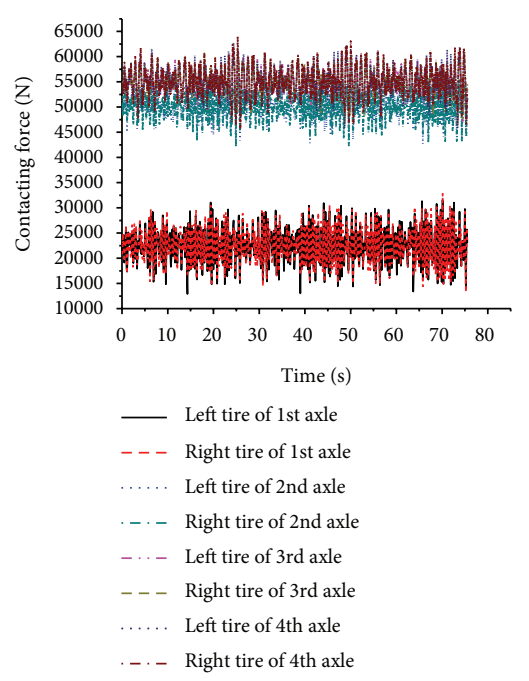

(f)

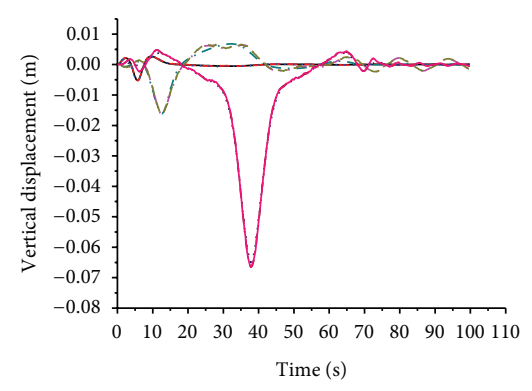

_ Static response at point $\mathrm{A}$

- - Dynamic response at point A $(I=3 \%)$

.... Coupling dynamic response at point A $(I=4 \%)$

.. - Static response at point B

-..- Dynamic response at point B $(I=1 \%)$

- - - Coupling dynamic response at point B $(I=2 \%)$

..... Static response at point $\mathrm{C}$

-. Dynamic response at point C $(I=2 \%)$

_ Coupling dynamic response at point C $(I=2 \%)$

(i)

FIgURE 7: Continued. 


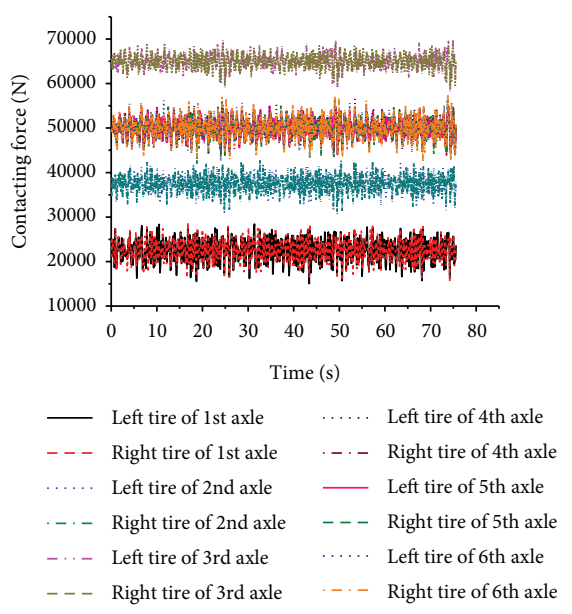

(j)

Figure 7: Time histories of responses using the vehicle-bridge coupling dynamic system: (a) vertical displacement of the bridge deck under the action of a 2-axle vehicle; (b) contacting force between the tires of a 2-axle vehicle and the bridge deck; (c) vertical displacement of the bridge deck under the action of a 3-axle vehicle; (d) contacting force between the tires of a 3-axle vehicle and the bridge deck; (e) vertical displacement of the bridge deck under the action of a 4-axle vehicle; (f) contacting force between the tires of a 4-axle vehicle and the bridge deck; (g) vertical displacement of the bridge deck under the action of a 5-axle vehicle; (h) contacting force between the tires of a 5-axle vehicle and the bridge deck; (i) vertical displacement of the bridge deck under the action of a 6 -axle vehicle; (j) contacting force between the tires of a 6-axle vehicle and the bridge deck.

different types of vehicles on the bridge are different. In view of the example, impact coefficients of 2-axle, 4-axle, and 6axle vehicles are relatively larger than others. The discussion of the influence of vehicle types and its regularity needs more bridge examples and should be paid more attention to when impact coefficients of ordinary beam bridges, which are more sensitive to the action of single vehicles, are studied. In general, with regard to the large cable-stayed bridge, impact coefficients of single vehicles are smaller than $5 \%$. It could be deemed as safe enough to set the impact coefficient of a single vehicle on a cable-stayed bridge at 5\%. But large cable-stayed bridges bear some features which short- and medium-span bridges do not. They are burdened with heavier traffic flows which consist of multiple vehicles. They have clustered frequencies and are sensitive to wind loads. The authors are more interested in whether the impact effect of a traffic flow on a cable-stayed bridge is evidently different from that of single vehicles on it. In a strong windy environment, vehicles' vibration excited by surface roughness couples with the bridge deck's buffeting caused by wind loads, which possibly exerts important influence on impact coefficients of traffic loads on a large cable-stayed bridge.

3.2. Impact Coefficients of Traffic Loads on the Bridge under the Action of Traffic Flows. The information of a traffic flow is often obtained from on-the-spot traffic investigations, which consume lots of human and financial resources. Modern highways are all equipped with tolling stations and the detailed traffic flow data are recorded in the database there. In fact, these data provide a convenient access to the traffic flow information, which is adopted in the paper. Based on the data during a day from the tolling station of the Sutong Yangtze

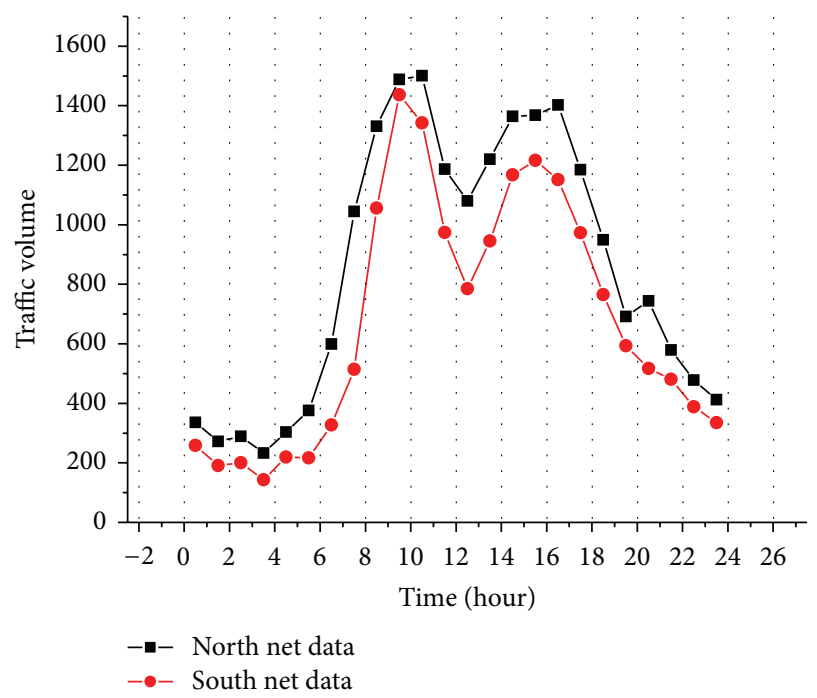

FIgURE 8: Traffic flow in every hour during a day.

Bridge, traffic volumes within 24 hours are given in Figure 8, in which north (south) net data denote the number of vehicles from the north (south). The figure shows that traffic volume from north is evidently larger than that from south in this day. There are two peaks in hourly traffic volume curves. One occurs from 9:00 to 10:00 a.m. and the other from 3:00 to 5:00 p.m. The former is the rush hour in a day. According to the pass time of vehicles, the traffic flow data during the rush hour are shown in Figure 9, in which vertical coordinates 26 denote 2-6 axle vehicles. Of course, an actual traffic flow is complex, and the vehicles' traveling velocity and intervals 


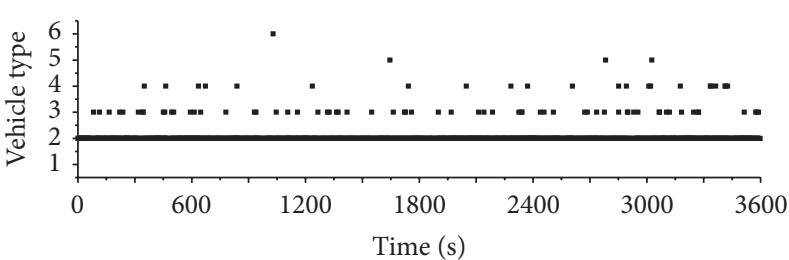

(a)

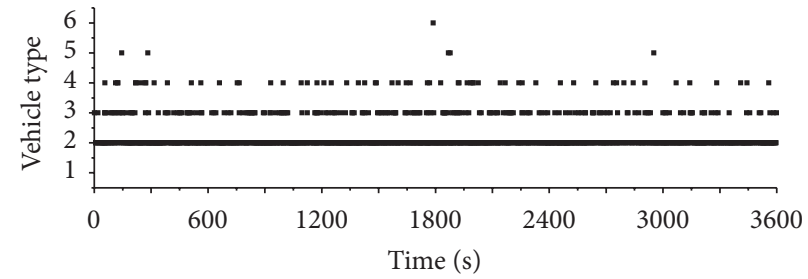

(b)

Figure 9: Traffic flow from 9:00 to 10:00: (a) north net data; (b) south net data.

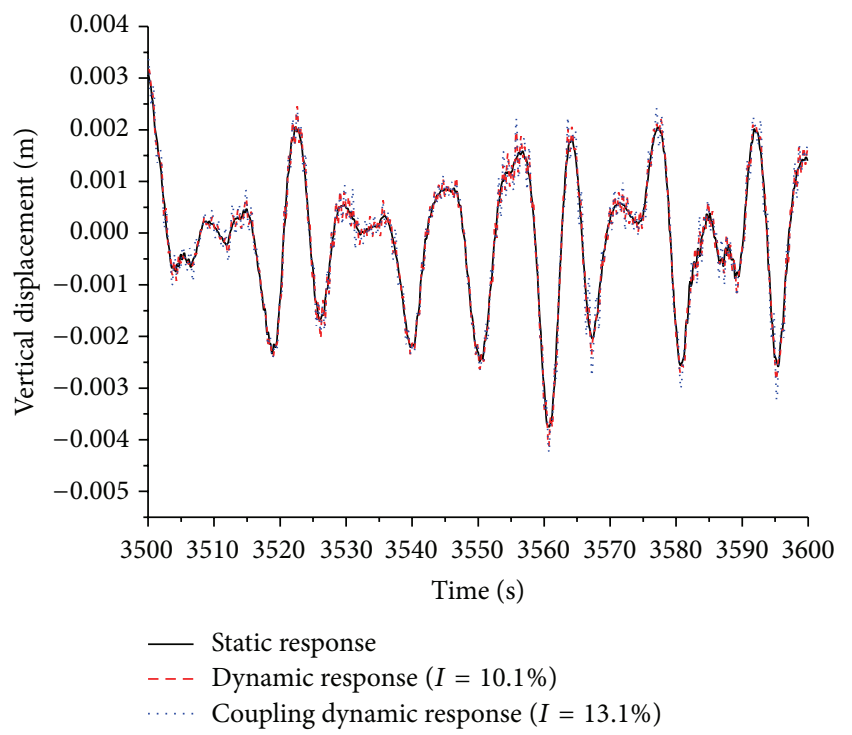

(a)

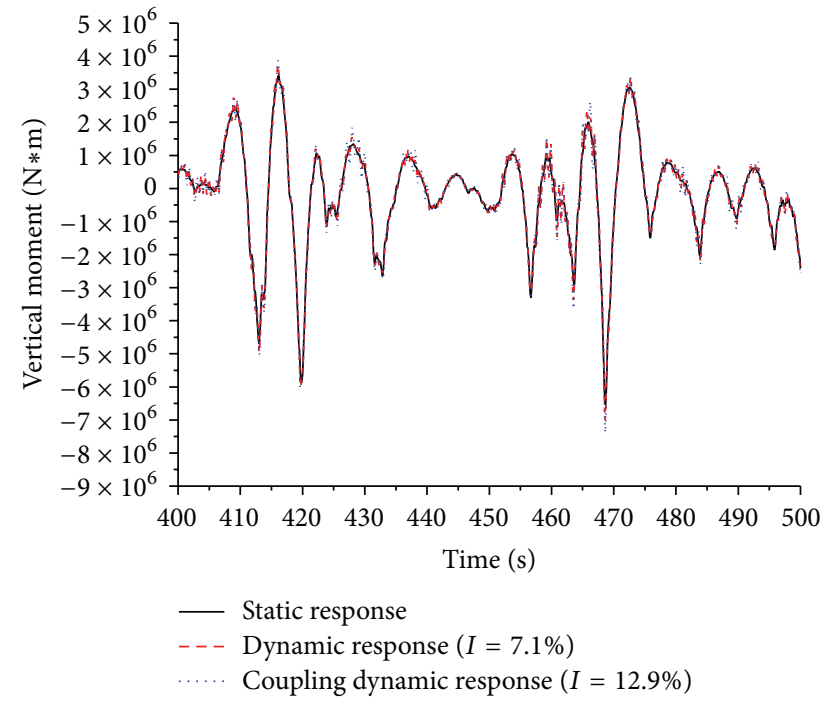

(c)

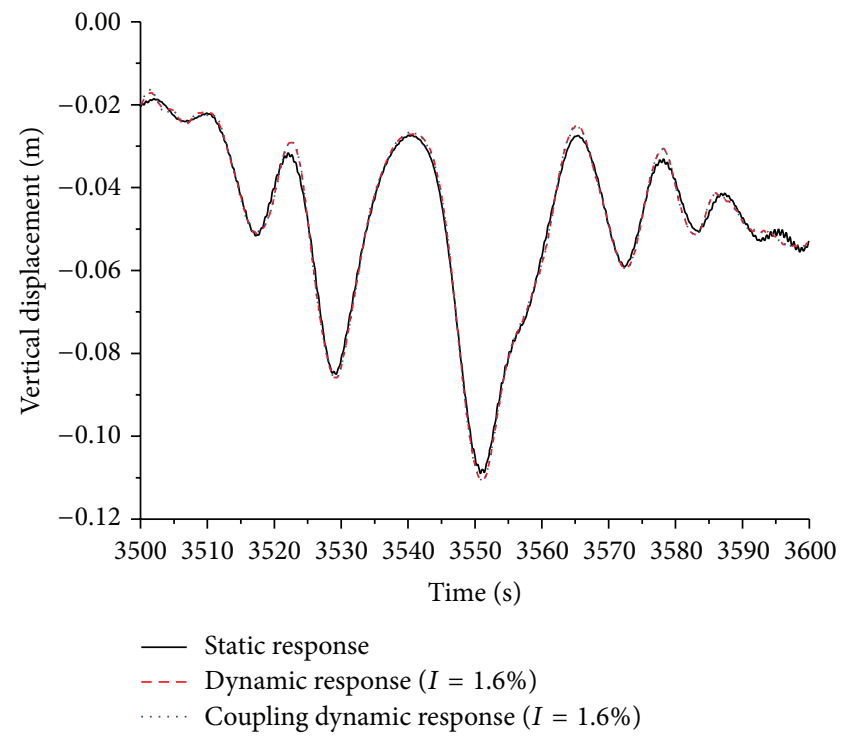

(b)

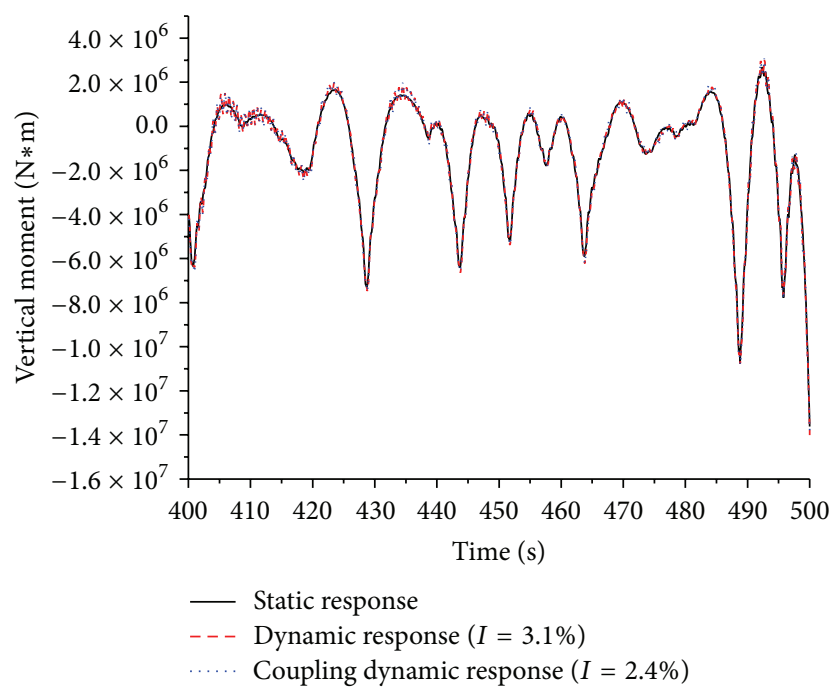

(d)

Figure 10: Time histories of responses of the bridge deck under the action of a traffic flow: (a) vertical displacement at point A; (b) vertical displacement at point $\mathrm{C}$; (c) vertical moment at point $\mathrm{A}$; (d) vertical moment at point $\mathrm{C}$. 


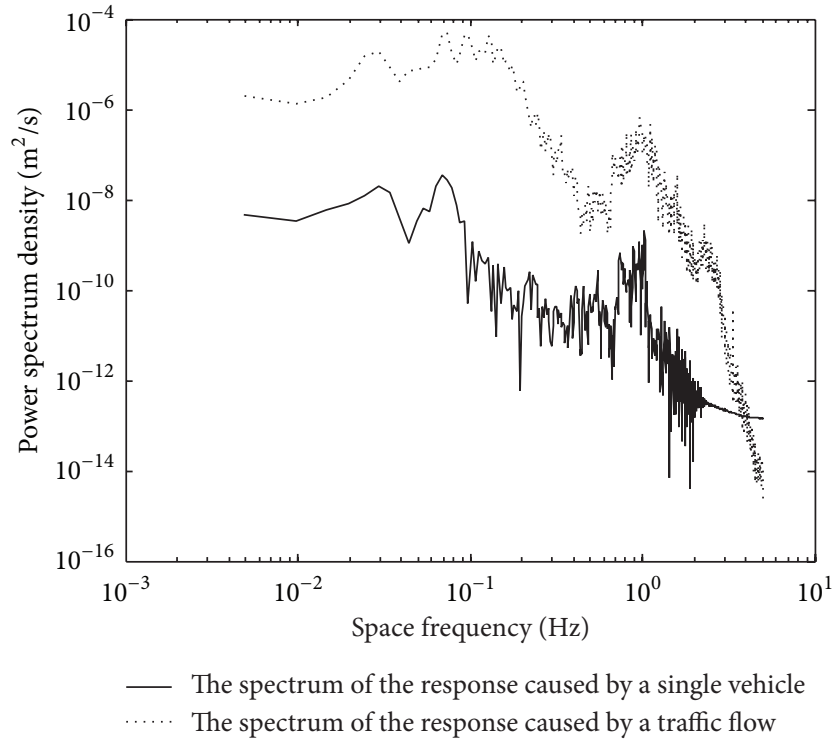

(a)

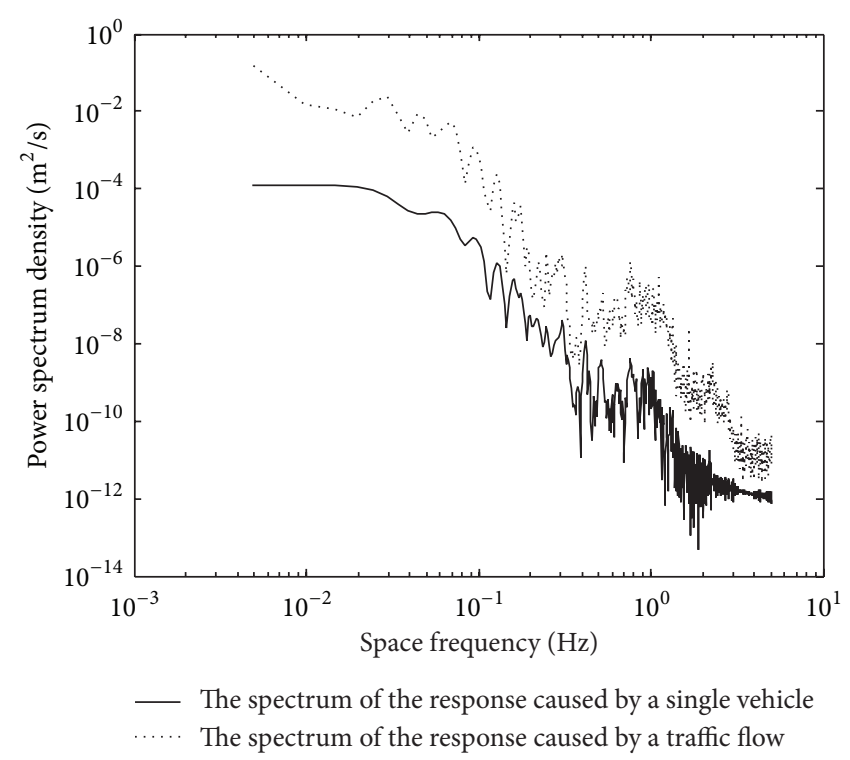

(b)

FIGURE 11: Power spectra densities of vertical displacement responses: (a) at point A; (b) at point C.

between them vary all the time. Figure 8 can only represent the traffic flow situation on one day and it is very possible that the traffic presents different characteristics on other days. However, the paper focuses on impact effect of traffic flows and wind loads on a cable-stayed bridge. It is unnecessary to pursue the traffic flow information of absolute precision. In the paper, the vehicles' traveling velocity is deemed as a constant. The influence of a traffic flow's intensity on impact coefficients will be discussed using the data during a day, which will be verified later.

This paragraph, by setting the traveling velocity at $100 \mathrm{~km} / \mathrm{h}$, calculates the dynamic and static responses of the bridge during the rush hour. The grade of surface roughness on the bridge deck is set as "good." The calculated results are partly shown in Figure 10. The figure shows that the impact effect of a 100-meter-long span under the action of a traffic flow is evidently larger than that under the action of a single vehicle and that the coupling effect exerts an evident influence on impact effect. The impact coefficients of vertical displacement and vertical moment responses are as large as $13 \%$ according to a part of the coupling dynamic responses given in Figure 10. However, the impact coefficients of the 1000-meter-long span are still smaller than 5\% under the action of a traffic flow.

To understand the reason why the impact effect caused by a traffic flow is apparently larger than that caused by a single vehicle (a 4-axle vehicle), the power spectrum densities of responses are analyzed. Figure 11(a) shows that there are two evident peaks in the 100-meter-long span's response spectrum caused by either the traffic flow or the single vehicle. One is between 0.07 and $0.2 \mathrm{~Hz}$; the other is around 1.0 Hz. Combining with Table 1, one can know that the former corresponds to low frequency vertical bending modes while the latter corresponds to high frequency ones. However, the power spectrum density of the response produced by a traffic flow is remarkably different from that produced by a single vehicle. The maximum value of the first peak band is about 10 times that of the second one in the $100 \mathrm{~m}$ long span's response spectrum produced by a single vehicle, while it is about 100 times in the spectrum caused by a traffic flow. It indicates that a traffic flow could excite more low frequency vertical bending modes, which accounts for the reason why a traffic flow can cause larger impact coefficients. Figure 11(b) shows that the 1000-meter-long span's response spectrum caused by the traffic flow presents a linearly declining trend and that there is no peak even around the basic frequency of the bridge $(0.19 \mathrm{~Hz})$ in the response spectrum, which indicates that there are little vibration ingredients in the $1000 \mathrm{~m}$ span's response.

3.3. Probabilistic Characteristics of Impact Coefficients of Traffic Flows on the Bridge. In the aforementioned discussions, the impact effect of several traffic flow samples on the bridge is analyzed, which could illustrate the influence of vehiclebridge coupling effect and surface roughness on impact effect. However, owing to the randomness of impact coefficients, the limited number of samples is not convincing enough to account for the influence of some parameters like traveling velocity and so forth on impact coefficients. Here, the traffic flow during a whole day is used and the traffic flow in every $100 \mathrm{sec}$ is taken as a sample. A total of $36 \times 24$ sample points of impact coefficients are obtained by coupling dynamic theory and then its probabilistic distribution is studied.

The traveling velocity is assigned at $100 \mathrm{~km} / \mathrm{h}$ and the grade of roughness is set as "good." The impact coefficients of the displacement at mid-span of the 100-meter-long span are given in Figure 12, in which the probabilistic distributions of impact coefficients in different time segments are provided. Figures 12(a) and 12(d) represent the situation at night with 


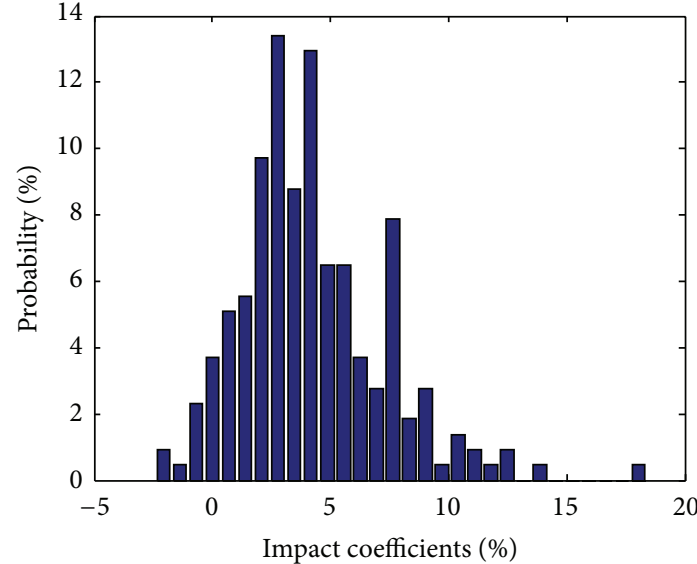

Considering coupling

Mean $=4.2 \%$, Std. $=3.1 \%$

(a)

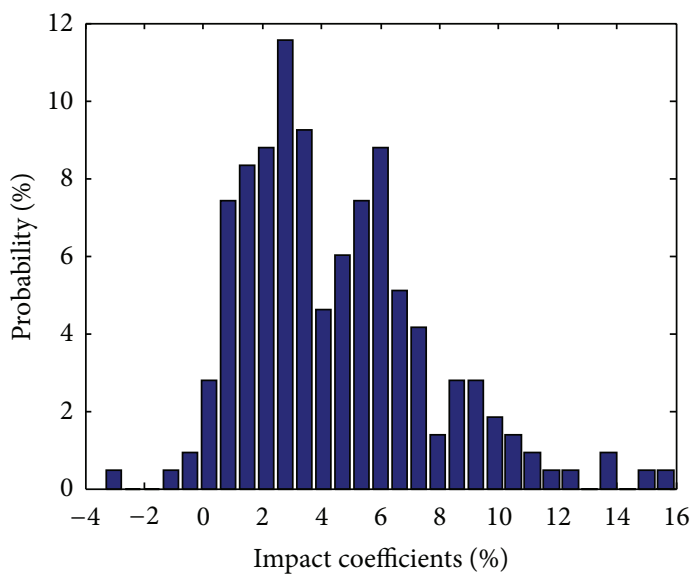

Considering coupling

Mean $=4.4 \%$, Std. $=3.2 \%$

(c)

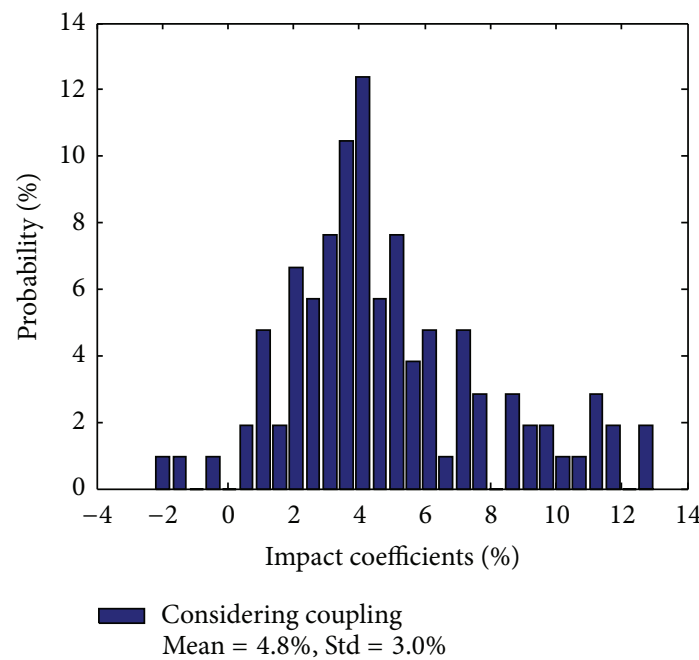

(e)

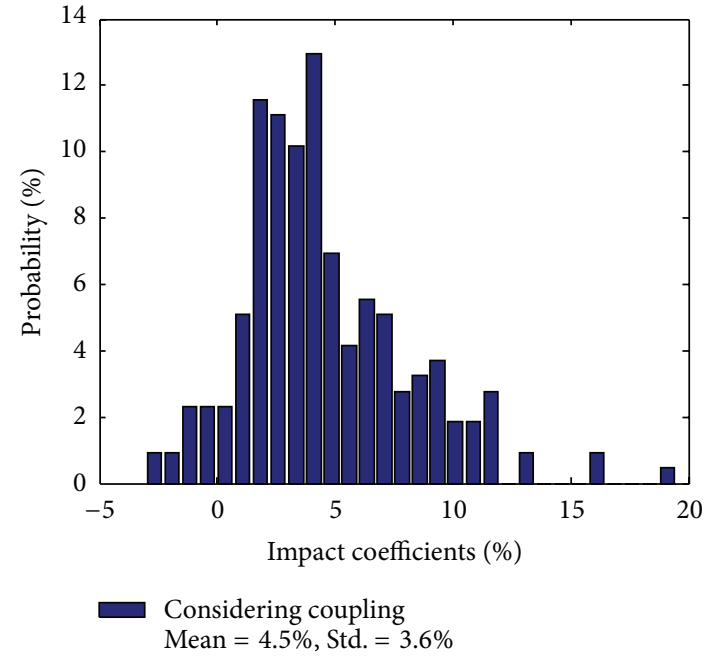

(b)

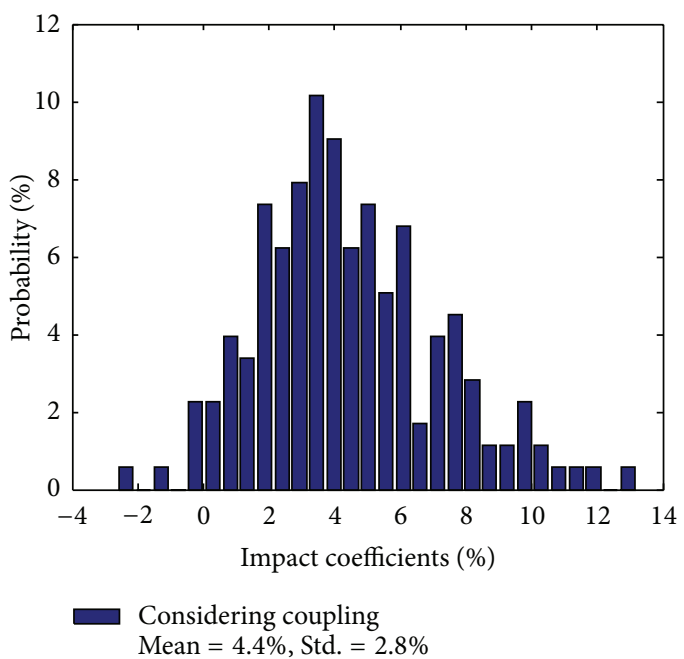

(d)

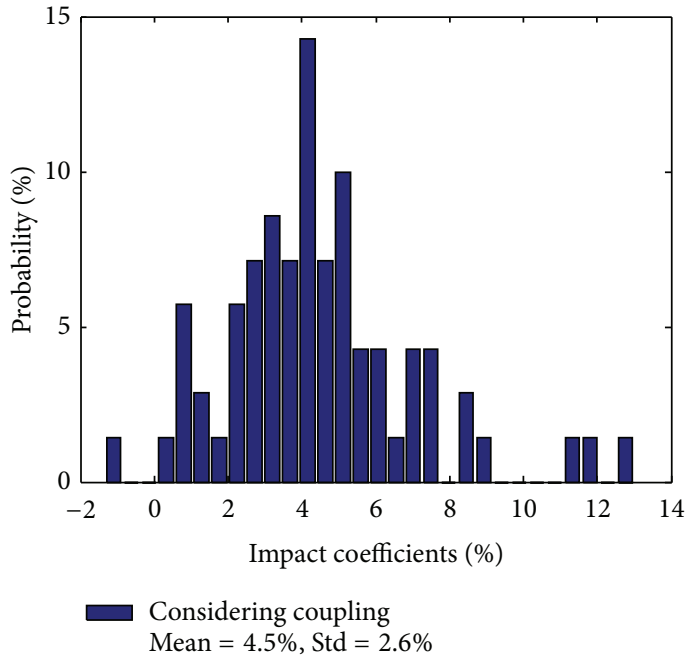

(f)

FIGURE 12: Probabilistic distributions of vertical displacement impact coefficients at point A of the bridge under the action of traffic flows in different time segments: (a) from 00:00 to 05:00; (b) from 06:00 to 11:00; (c) from 12:00 to 17:00; (d) from 18:00 to 23:00; (e) from 09:00 to 11:00; (f) from 09:00 to 10:00. 


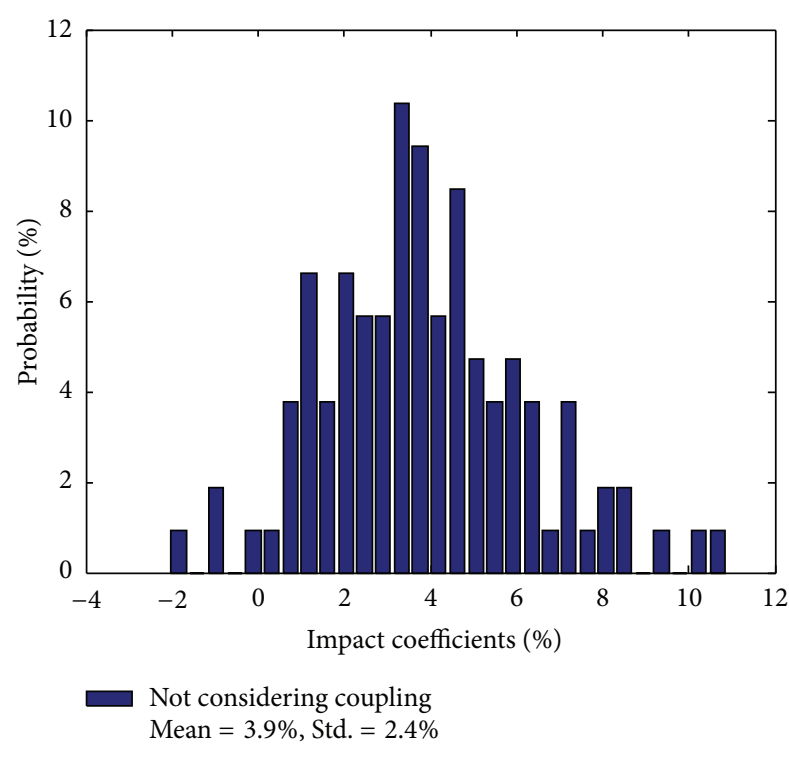

(a)

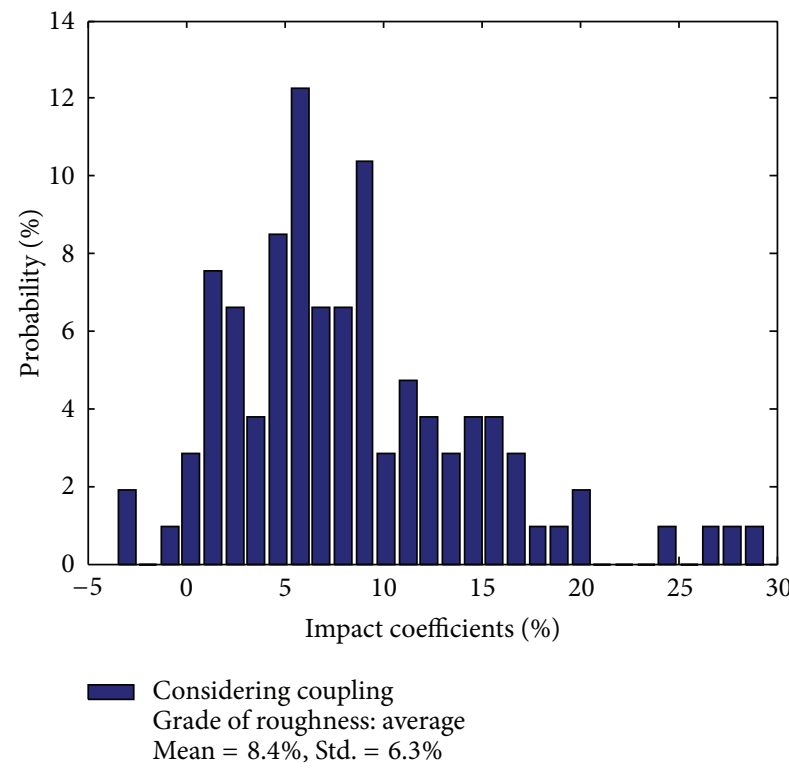

(c)

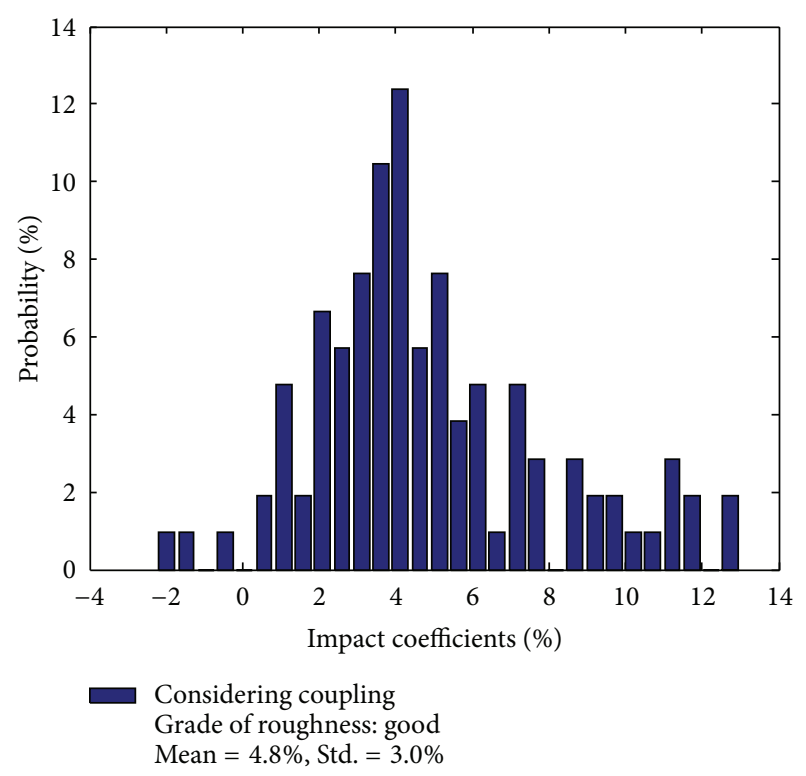

(b)

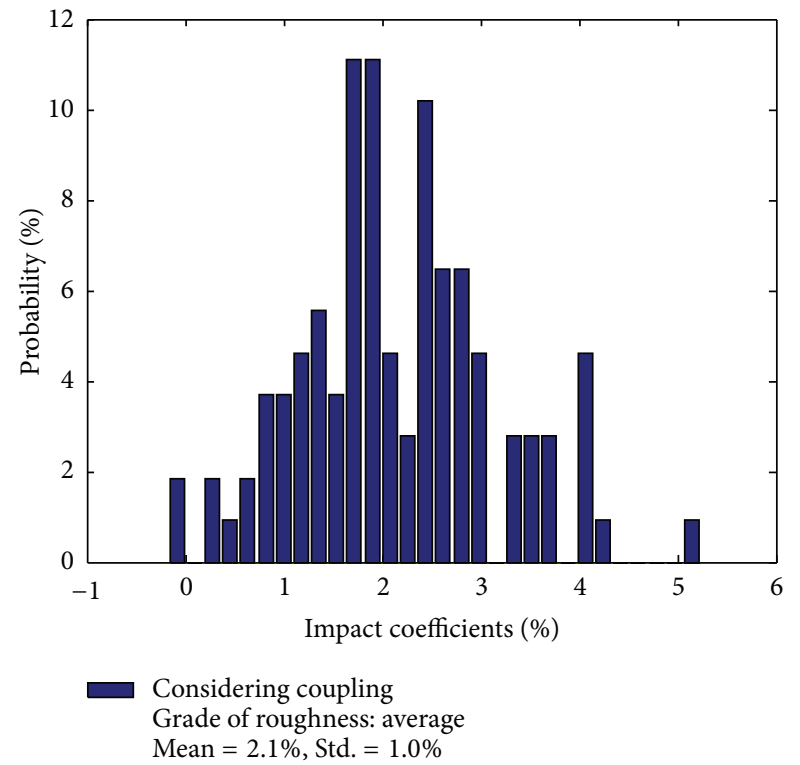

(d)

FIGURE 13: Probabilistic distributions of vertical displacement impact coefficients of the bridge under the conditions of different surface roughness: (a) at point $\mathrm{A}$; (b) at point $\mathrm{A}$; (c) at point $\mathrm{A}$; (d) at point $\mathrm{C}$.

less traffic while Figures 12(b) and 12(c) represent that in the daytime with heavy traffic. By comparing the results of the 4 time segments, one finds that the standard deviations of impact coefficients caused by heavy traffic flows are a little larger than those by sparse traffic flows while their mean values are almost the same. Figures $12(\mathrm{e})$ and $12(\mathrm{f})$ give the distributions of impact coefficients of traffic flows on the 100 -meter long-span during shorter time segments. When the time is as long as 2 or 3 hours, that is, the number of sampling points is $36 \times 2-36 \times 3$, its mean and standard deviation are almost stabilized. The traffic flows during 9:00 and 11:00 a.m. are used in the following part, when the traffic is the heaviest over the bridge. However, it is also proved reasonable to suppose that the probabilistic distribution of impact coefficients of a traffic flow on a bridge is independent on its intensity. So when enough data about traffic flows were not provided at a tolling station, one could randomly investigate the traffic flow data within 2-3 hours.

Figure 13 presents the distributions of vertical displacement impact coefficients of the bridge under the conditions of different surface roughness. Figure 14 presents the probabilistic distributions of vertical moment impact coefficients at point $\mathrm{A}$. The results further make it clear that vehiclebridge coupling effect and the grade of surface roughness 


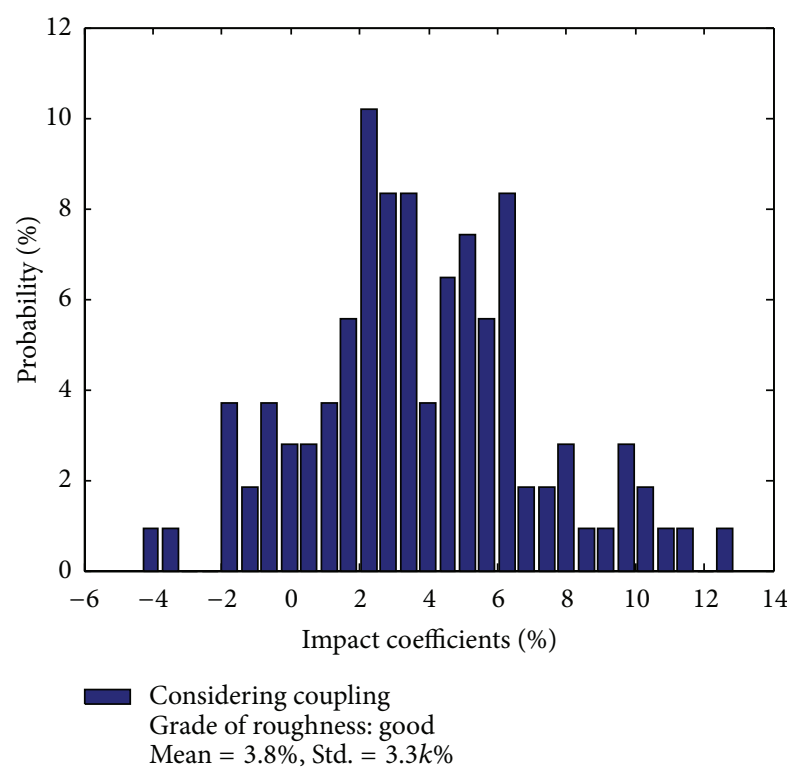

(a)

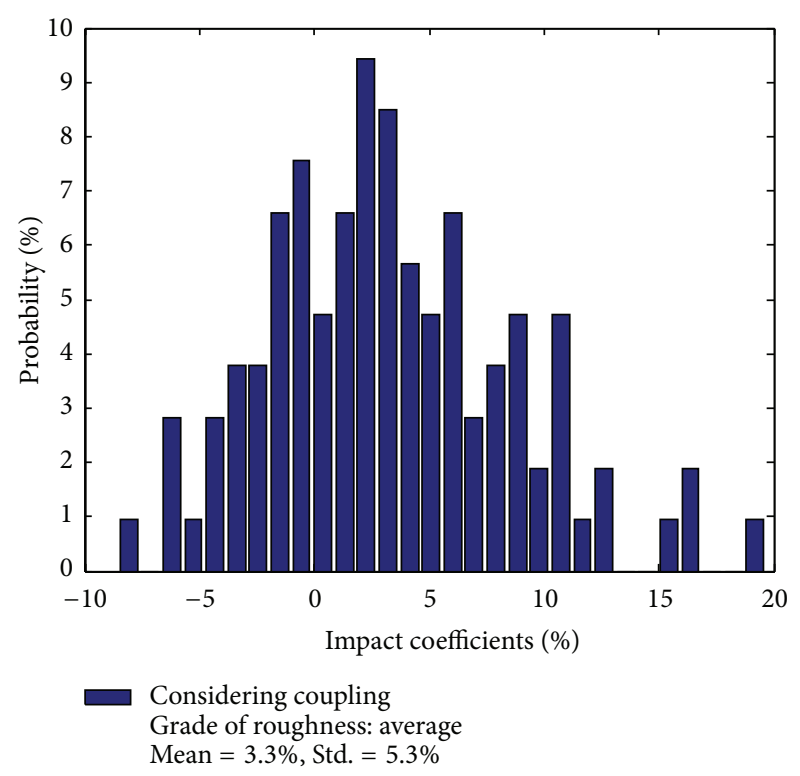

(b)

FIGURE 14: Probabilistic distribution of vertical moment impact coefficients at point A of the bridge under the conditions of different surface roughness: (a) good; (b) average.

exert remarkable influence on impact coefficients of traffic loads on the $100 \mathrm{~m}$ span of the cable-stayed bridge. When the grade of surface roughness is "good," impact coefficients of traffic loads are generally no more than $20 \%$. When the grade is "average," the maximum impact coefficient of traffic loads on the $100 \mathrm{~m}$ span of the bridge is even up to $30 \%$. However, the impact coefficients of traffic loads on the 1000-meterlong span are smaller than $5 \%$ in a windless environment. The reason is that the frequencies of the $1000 \mathrm{~m}$ span are much lower than those of vehicles' vibration. The $1000 \mathrm{~m}$ span presents noticeably different characteristics in a strong windy environment, which will be analyzed in detail later in this paper.

Figure 15 presents the distributions of impact coefficients of traffic flows on the $100 \mathrm{~m}$ span at different traveling velocities. Although the impact coefficient bears the feature of randomness, its probabilistic distribution illustrates that traveling velocity exerts regular influence on the impact effect. With traveling velocity rising, both the mean values and standard deviations of impact coefficients increase.

\subsection{Impact Coefficients of Traffic Loads on the Bridge in a} Strong Windy Environment. To calculate the time history responses of the bridge under the action wind loads, the stochastic wind velocity field needs to be simulated. The spectrum representation method developed by Deodatis [14] is adopted here. By referring to the literature [15], the lateral wind spectrum adopted is in Kainmal's form; the vertical spectrum adopted is in the form presented by Lumley and Panofsky. The coherence function adopted is in Davenport's form in which the correlation coefficient is set to 7.0. The dynamic responses of the bridge under the action of wind loads at a mean wind velocity of $49.8 \mathrm{~m} / \mathrm{s}$, which is the design wind velocity for the Sutong Yangtze Bridge, are analyzed. The results are partly shown in Figure 16. The figure shows that both the vertical and lateral responses at point $\mathrm{C}$ under the action of wind loads fluctuate around their mean values, respectively. However, their mean values are not zero and the nonzero mean values are caused by static wind loads. The vertical static response caused by wind loads is smaller than the lateral one. Yet the amplitude of the vertical dynamic response caused by turbulent wind is much larger than that of the lateral one. The reason is that the lift item of the bridge deck's aerodynamic coefficients is more sensitive to wind attack angle than the drag and torque items and the derivative of the lift coefficient with respect to the wind attack angle is larger than those of the other two. The bridge deck's selfexcited force, which is caused by the mechanism of fluid-solid coupling, makes the vertical buffeting decrease evidently. It indicates that fluid-solid coupling restraints the buffeting of the bridge deck at the design wind velocity.

By using one sample of the traffic data in 10 min during the above-mentioned rush hour, the responses produced by wind loads and caused by the traffic flow are compared. Figure 17 shows that when the mean wind velocity is $20 \mathrm{~m} / \mathrm{s}$, the main span's buffeting responses caused by turbulent wind are comparative with that caused by the traffic flow. When the mean wind velocity increases to $30 \mathrm{~m} / \mathrm{s}$ or $49.8 \mathrm{~m} / \mathrm{s}$, the main span's buffeting responses caused by turbulent wind become much larger, even larger than that caused by the traffic flow. In these conditions, the wind loads become one of the main loads. Figure 17(c) offers the contacting force responses between a 4-axle vehicle and the bridge deck in the strong windy environment. Figure 17(d) shows roughness and additional roughness, which is caused by the bridge deck's motion, of a contacting point of one tire. All 


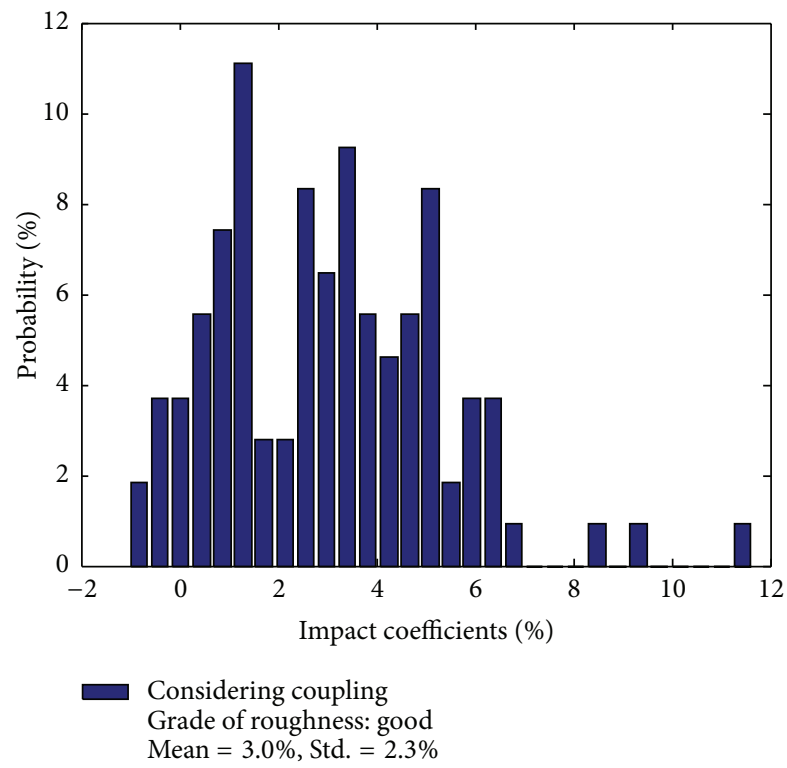

(a)

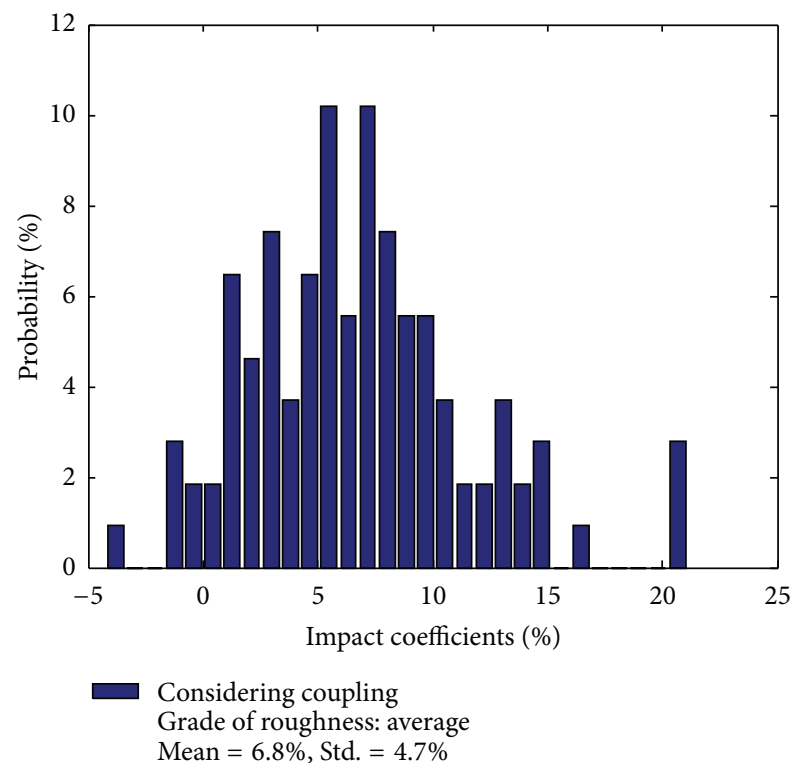

(c)

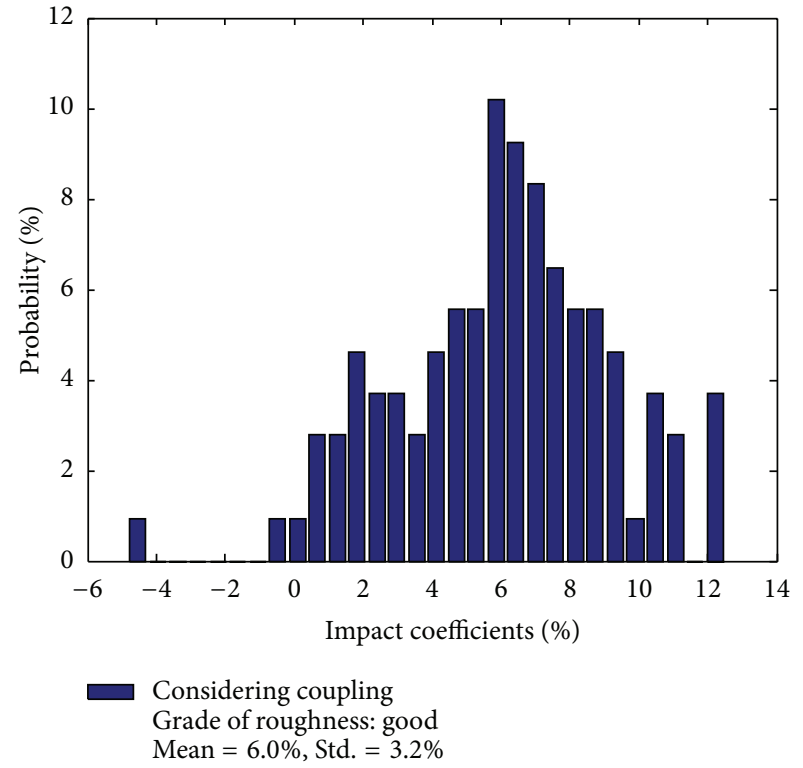

(b)

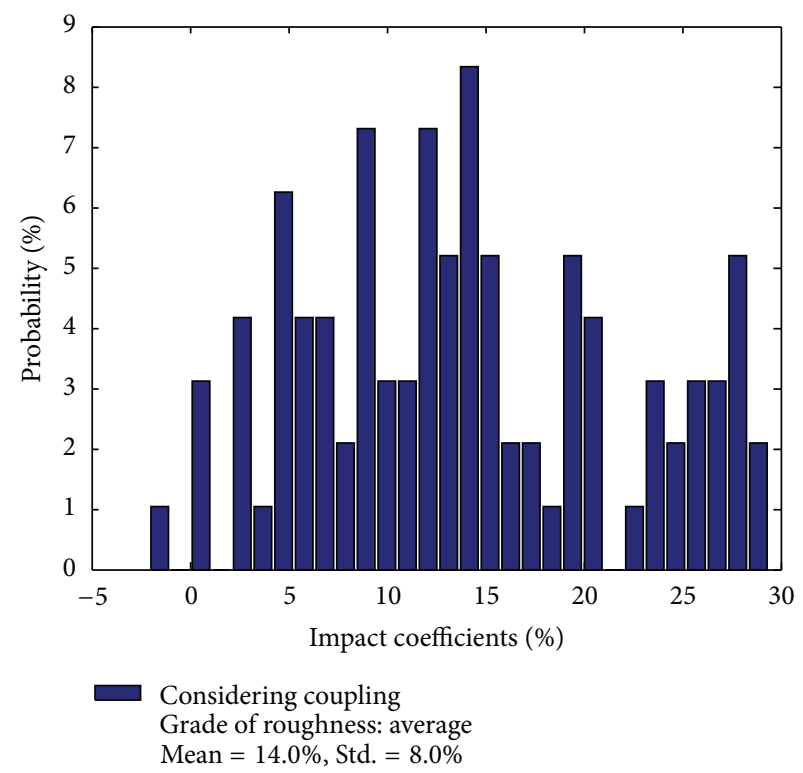

(d)

FIGURE 15: Probabilistic distributions of vertical displacement impact coefficients at point A of the bridge at different traveling velocities: (a) $80 \mathrm{~km} / \mathrm{h}$; (b) $120 \mathrm{~km} / \mathrm{h}$; (c) $80 \mathrm{~km} / \mathrm{h}$; (d) $120 \mathrm{~km} / \mathrm{h}$.

contacting responses of the tires are positive, which presents the correctness of assumption that all tires of vehicles always keep in touch with the bridge deck.

Moreover, it could be observed that the frequencies of the 1000-meter-long span's buffeting are much higher than those of its response under the action of a traffic flow. So there exists a coupling phenomenon between the bridge deck buffeting and vehicle vibrations. The wind-vehicle-bridge coupling vibration is further analyzed. To analyze the problem clearly, the buffeting response at point $\mathrm{C}$ caused by wind loads is subtracted from the dynamic response produced by the joint action of wind loads and the traffic flow. The subtraction is also the response produced by the traffic flow, in which the coupling between the bridge buffeting and vehicle oscillation is taken into consideration. Figure 18 compares the bridge deck's response caused by the traffic flow in a windy environment and that in a windless environment. When the mean wind velocity is $20 \mathrm{~m} / \mathrm{s}$, there is no obvious difference between the results from the wind-vehicle-bridge coupling analysis and the vehicle-bridge coupling one. However, when the mean wind velocity rises to $30 \mathrm{~m} / \mathrm{s}$, the maximum impact coefficient obtained from the wind-vehicle-bridge analysis is $13 \%$, much larger than that from the vehicle-bridge one. When the mean wind velocity is $49.8 \mathrm{~m} / \mathrm{s}$, the maximum 


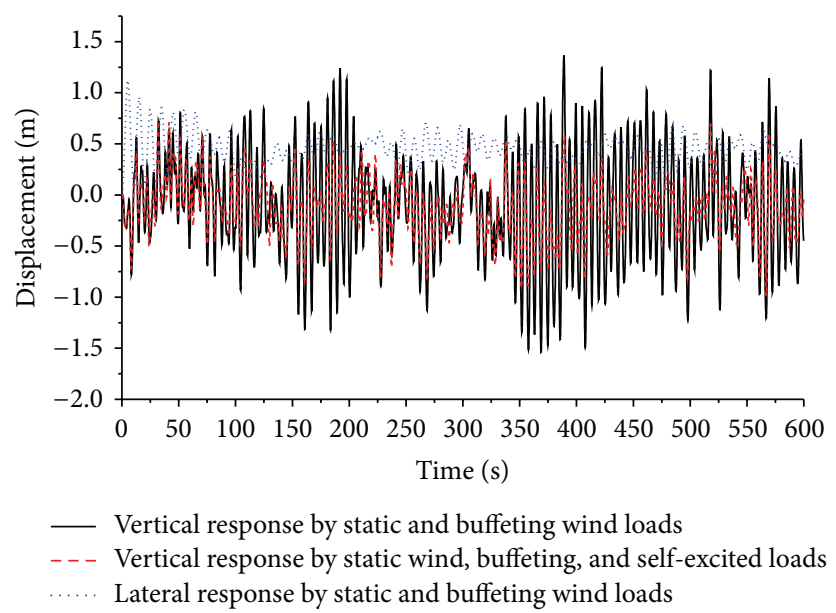

Figure 16: Time histories of dynamic responses produced by wind loads at point $\mathrm{C}(U=49.8 \mathrm{~m} / \mathrm{s})$.

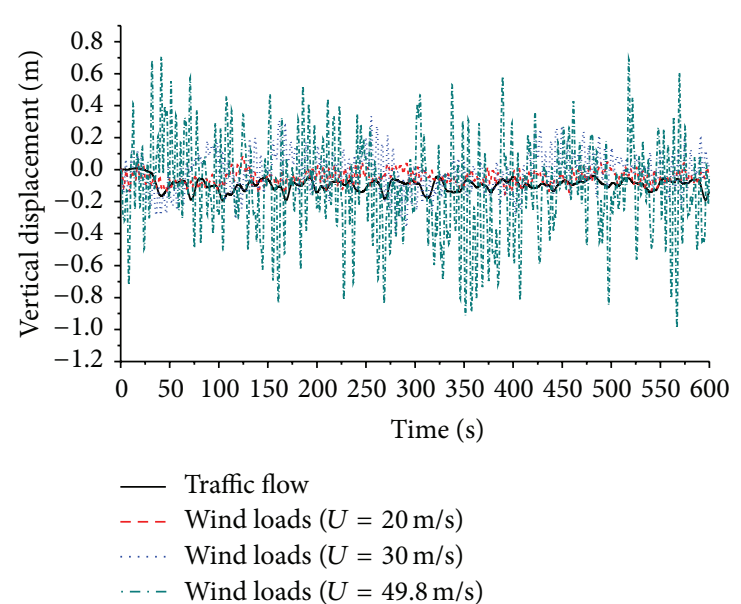

(a)

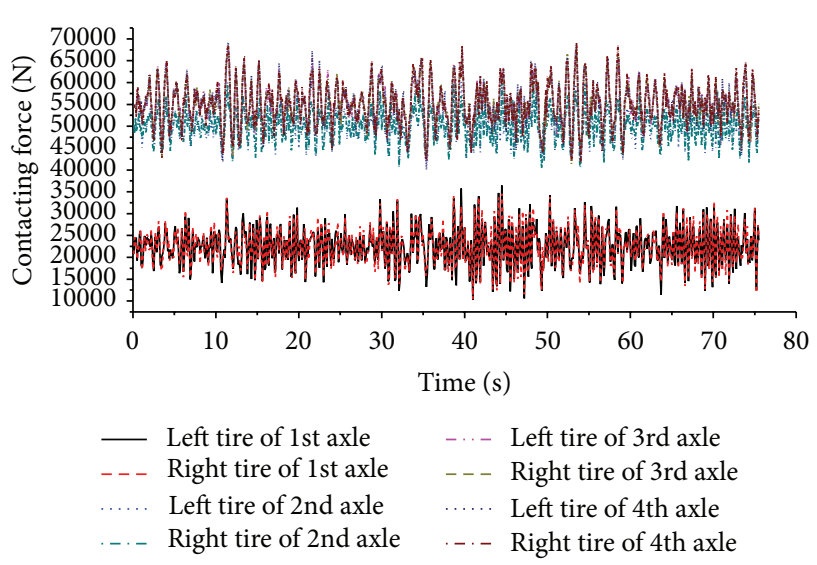

(c)

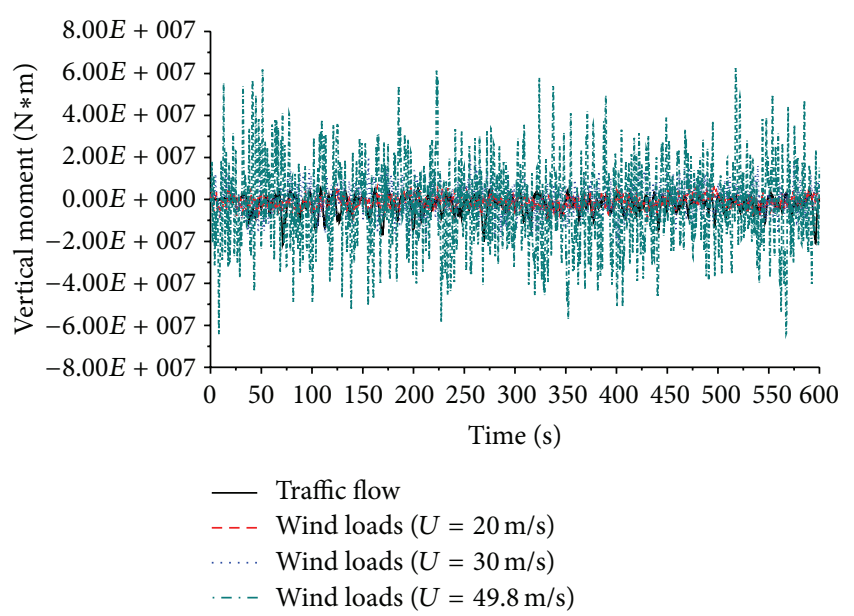

(b)

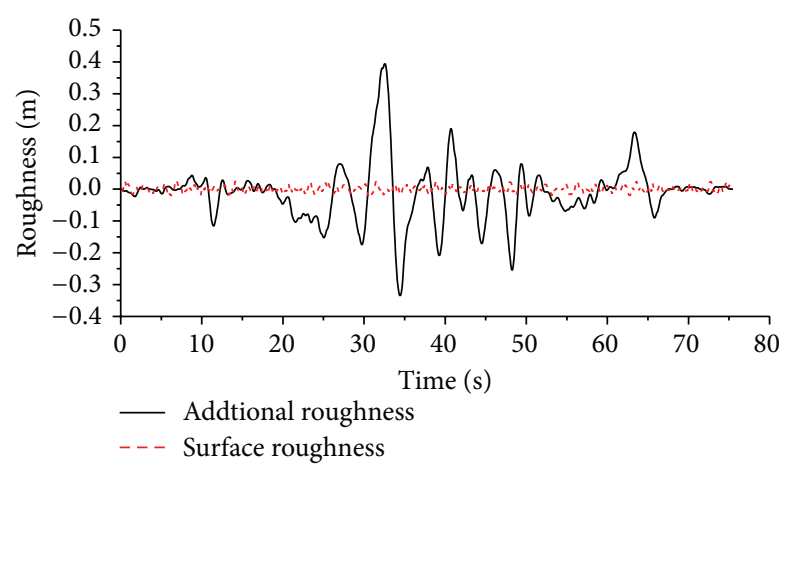

(d)

FIGURE 17: Time histories of responses at point $\mathrm{C}$ of the bridge under the action of wind loads and traffic flows: (a) vertical displacement; (b) vertical moment; (c) contacting force of a 4-axle vehicle with the bridge deck at the wind velocity of $49.8 \mathrm{~m} / \mathrm{s}$; (d) surface roughness and additional roughness at one of the contacting points of a 4 -axle vehicle's tires with the bridge deck. 


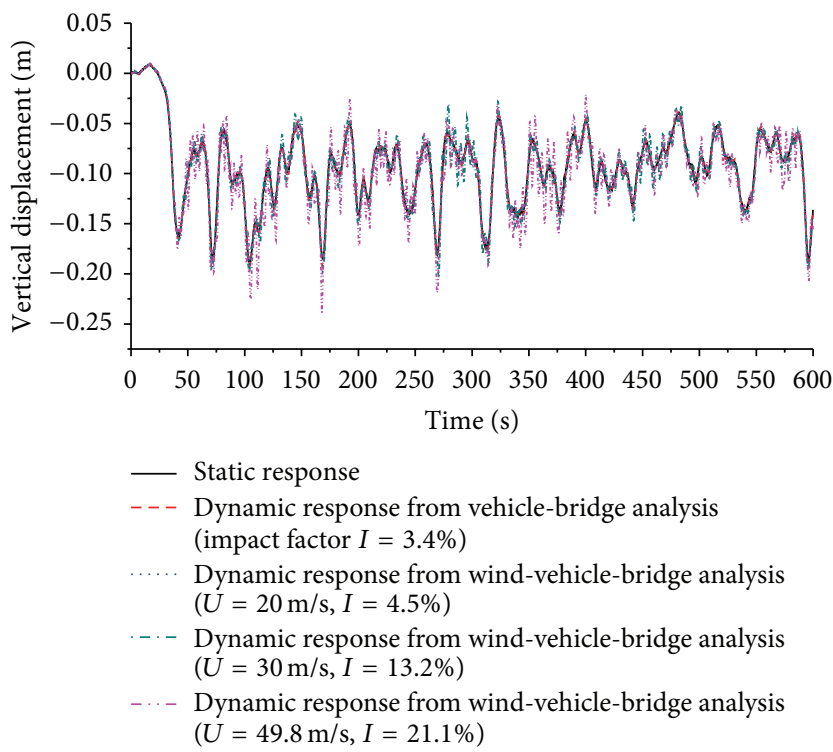

FIGURE 18: Time histories of vertical displacement responses caused by the traffic flow at point $\mathrm{C}$ in a windy or windless environment.

impact coefficient obtained from the wind-vehicle-bridge analysis is as large as $21 \%$. The grade of roughness is set to "good" in the calculation here.

Then the probabilistic distribution of the $1000 \mathrm{~m}$ span's impact coefficients obtained from the wind-vehicle-bridge coupling analysis is studied. The traffic flow data in 3 hours is used and the mean wind velocity is assigned at 30 and $49.8 \mathrm{~m} / \mathrm{s}$, respectively. The grade of roughness is set to "good" and "average," respectively. A traffic flow in every $100 \mathrm{sec}$ is taken as a sample and the probabilistic distribution is provided in Figures 19 and 20. By comparing Figures 13(d), 19 , and 20 , one could conclude that the coupling between vibrations of vehicles and the buffeting of the bridge deck exerts remarkable influence on the impact effect of a traffic flow on the bridge, and the influence becomes more obvious when the wind velocity rises. The reason may lie in that the self-excited force plays a more important role in wind loads when the wind velocity is large, which makes the frequency ingredients of the bridge deck's vibration change. In this case, it becomes easier for vehicles' vibration to couple with the movement of the bridge's 1000-meter span. Figure 19 also presents that the grade of surface roughness exerts little influence on impact coefficients of traffic loads on the $1000 \mathrm{~m}$ span and thus the vehicle-bridge coupling becomes a decisive factor for the impact effect on the bridge's $1000 \mathrm{~m}$ span in a strong windy environment.

Impact coefficients calculated by using dynamic analysis in this paper are further compared with the results derived from code provisions in bridge design specifications. Currently, the impact coefficients are calculated based on a bridge's basic frequency or its length in design specifications. The main span of the Sutong Yangtze Bridge's main channel is 1008 meters long. According to AASHTO-1996 [16], the impact coefficient should be $1.46 \%$. The frequencies of the first two vertical bending modes of the Sutong Yangtze Bridge are $0.18 \mathrm{~Hz}$ and $0.22 \mathrm{~Hz}$, respectively, and the frequencies of the first two vertical bending modes embodying the side span bending, that is, the 47 th and 48th modes, are also smaller than or close to $1.0 \mathrm{~Hz}$. According to JTG D60-2004 [17], the impact coefficient is $5 \%$. However, according to OHBDC1983 [18], the impact coefficient should be $20 \%$ for such a bridge. In view of the results derived from above-mentioned dynamic analysis, with regard to a large cable-stayed bridge, it is suggested that the impact coefficient of traffic loads takes the value of $25 \%$.

\section{Conclusions}

A mathematical method is developed to analyze the impact coefficient of a cable-stayed bridge. A wind-vehicle-bridge coupling analysis system is developed to take a random highway traffic flow into consideration. By taking the Sutong Yangtze Bridge as an example, impact coefficients of different spans of this large cable-stayed bridge are studied by the newly developed coupling analysis system, and the coupling between vehicles' vibration and the bridge deck's buffeting is paid due attention to. The calculated results are compared with the values stipulated in the relevant code clauses in bridge design specifications. The conclusions are as follows.

(1) Impact coefficients of a random traffic flow on a 100meter-long span are much larger than those of single vehicles on it. There are two peaks in the response spectrum of a $100 \mathrm{~m}$ span under the action of either a traffic flow or a single vehicle: one corresponds to low frequency vertical bending modes and the other corresponds to high frequency ones. In the response spectrum produced by a single vehicle, the first peak is about 10 times that of the second one in value. This ratio increases to about 100 times in the response spectrum produced by a traffic flow. It indicates that a traffic flow could excite more low frequency vertical bending modes, which is the reason why the impact effect caused by a traffic flow is much larger than that by a single vehicle. 


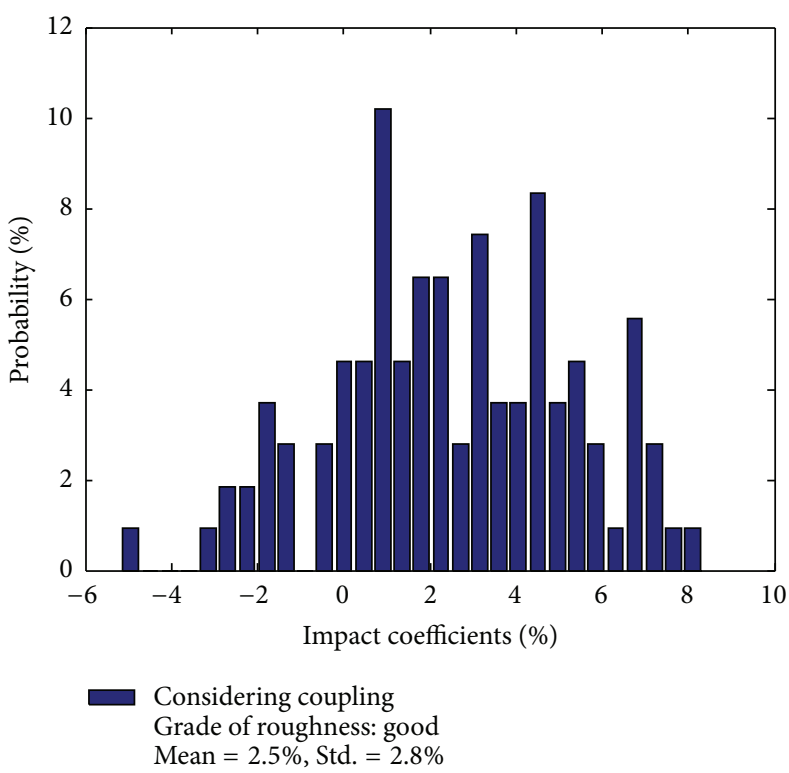

(a)

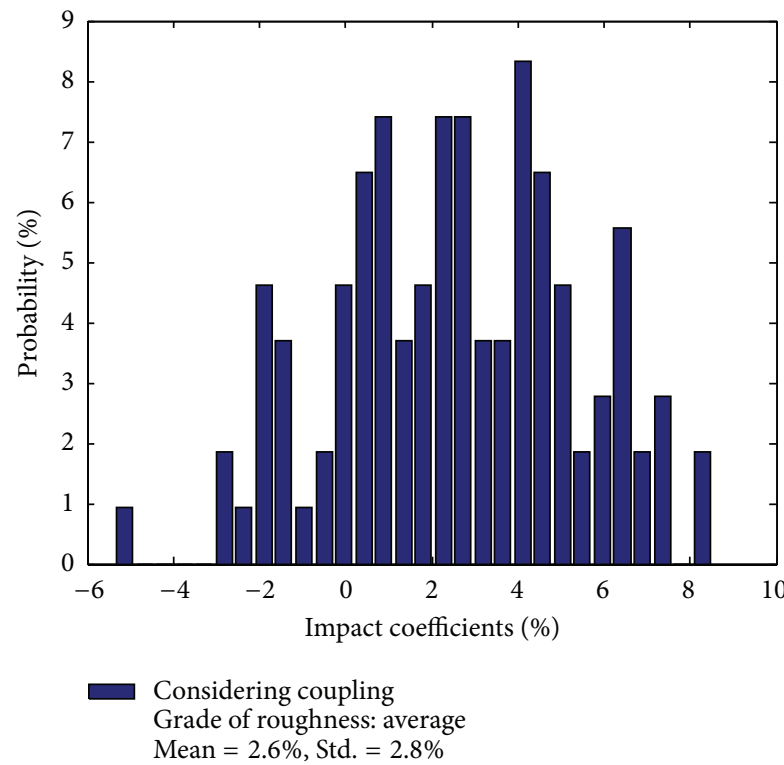

(c)

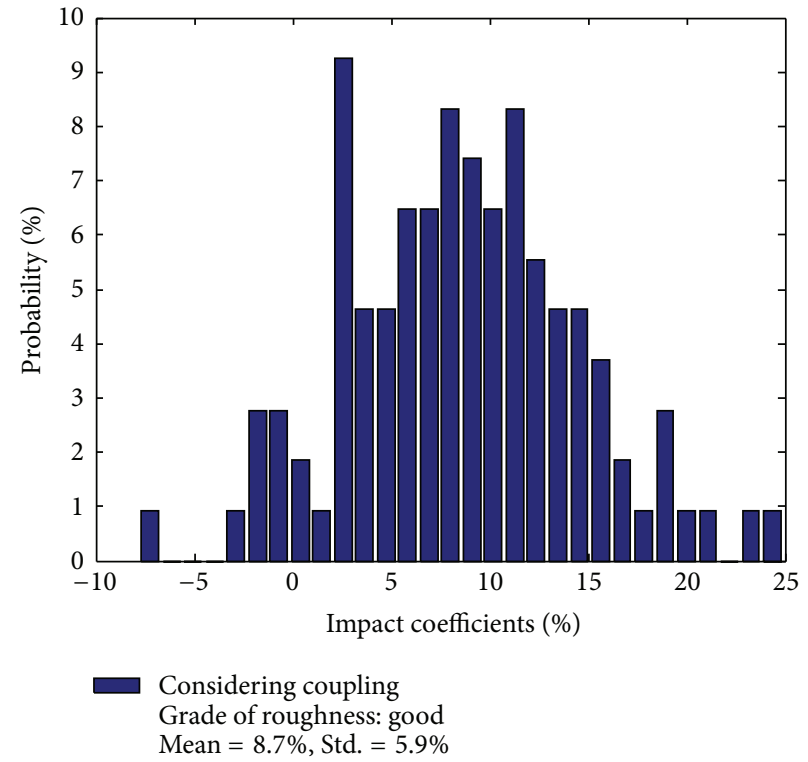

(b)

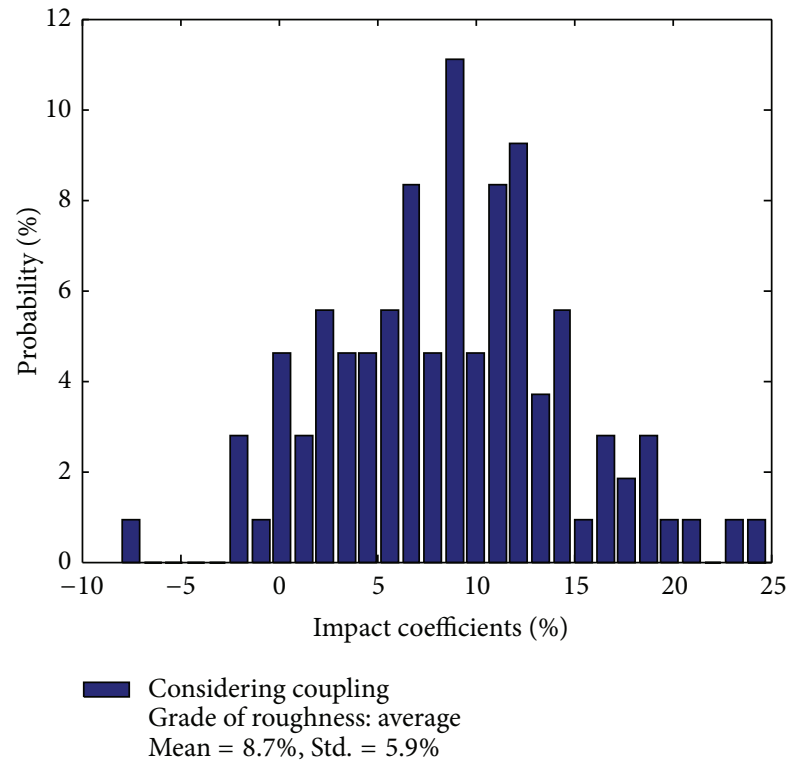

(d)

FIgURE 19: Probabilistic distributions of vertical displacement impact coefficients at point $\mathrm{C}$ of the bridge in a windy environment: at the mean wind velocity of (a) $30 \mathrm{~m} / \mathrm{s}$; (b) $49.8 \mathrm{~m} / \mathrm{s}$; (c) $30 \mathrm{~m} / \mathrm{s}$; (d) $49.8 \mathrm{~m} / \mathrm{s}$.

(2) Impact coefficients bear the feature of randomness, so the probabilistic distribution of impact coefficients, which are based on large numbers of samples, could interpret the influence of various kinds of factors more clearly. It is presented that standard deviations of impact coefficients of heavy traffic flows are a little larger than those of sparse traffic flows while their mean values are almost the same. So it is reasonable to suppose that the probabilistic distribution of traffic flows' impact coefficients on a bridge is independent on the traffic intensity. With traveling velocity rising, both mean values and standard deviations of traffic flows' impact coefficients on a bridge increase. Vehicle-bridge coupling effect and the grade of surface roughness exert important influence on impact coefficients of traffic loads on a cable-stayed bridge. When the grade of surface roughness is "good," the impact coefficients are no more than $20 \%$. When the grade is "average," the maximum impact coefficient on the $100 \mathrm{~m}$ span is even up to $30 \%$. However, the impact coefficients of traffic loads on the 1000 -meter-long span are smaller than $5 \%$ in a windless environment.

(3) The cable-stayed bridge's static vertical response produced by wind loads is smaller than the lateral one. But the amplitude of the bridge's vertical buffeting response caused by turbulent wind is much larger than that of the lateral 


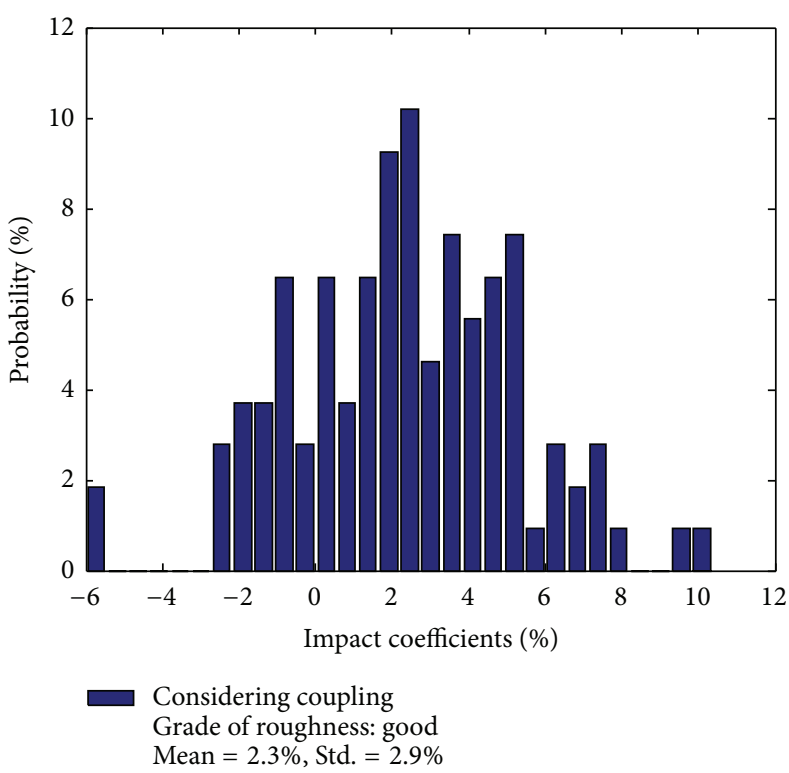

(a)

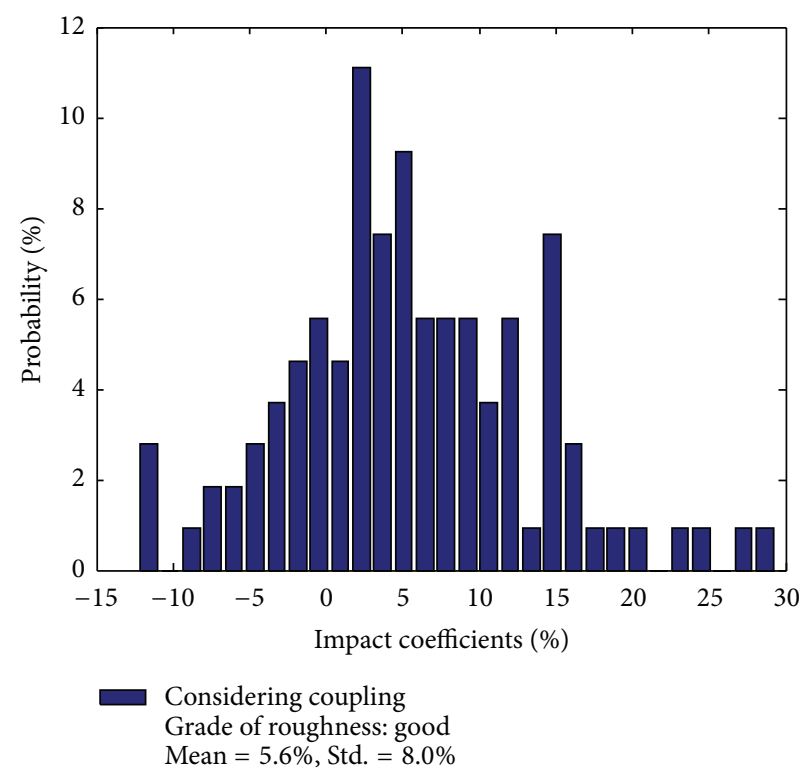

(b)

FIgURE 20: Probabilistic distributions of vertical moment impact coefficients at point $\mathrm{C}$ of the bridge in a windy environment: at the mean wind velocity of (a) $30 \mathrm{~m} / \mathrm{s}$; (b) $49.8 \mathrm{~m} / \mathrm{s}$.

one. When the mean wind velocity is more than $30 \mathrm{~m} / \mathrm{s}$, the 1000-meter-long span's buffeting response is much larger than its response caused by a traffic flow. And there exists a coupling phenomenon between the vibration of vehicles and the buffeting of the bridge deck, which makes that impact coefficients of traffic loads on the $1000 \mathrm{~m}$ span of the cable-stayed bridge become as large as $25 \%$ in a strong windy environment. Grade of surface roughness exerts little influence on impact coefficients of traffic loads on the $1000 \mathrm{~m}$ span and thus the vehicle-bridge coupling effect becomes a decisive factor for impact effect of traffic loads on a cablestayed bridge in a strong windy environment.

(4) Impact coefficients calculated by the coupling dynamic analysis system are compared with the results derived from bridge design specifications. According to results obtained from coupling dynamic analysis in the paper, a preliminary conclusion is drawn that the impact coefficient should be $25 \%$ for a large cable-stayed bridge. Impact effect of a large cable-stayed involves many factors. Some important factors and relevant regularities are discussed and some conclusions are drawn in the paper. However, only one cable-stayed bridge is taken as an example. More examples should be studied before rational suggestions about impact coefficients of traffic loads on a cable-stayed bridge are provided to bridge designers. The problems analyzed in the paper should also be paid due attention to when the impact effect of other types of bridges is studied.

\section{Conflict of Interests}

The authors declare that there is no conflict of interests regarding the publication of this paper.

\section{Acknowledgment}

The authors acknowledge the financial contribution by Grant of China National Natural Science Foundations (51108154, 51278064).

\section{References}

[1] D. Chang and H. Lee, "Impact factors for simple-span highway girder bridges," Journal of Structural Engineering, vol. 120, no. 3, pp. 704-715, 1994.

[2] M. Fafard, M. Laflamme, M. Savard, and M. Bennur, "Dynamic analysis of existing continuous bridge," Journal of Bridge Engineering, vol. 3, no. 1, pp. 28-37, 1998.

[3] S. S. Law and X. Q. Zhu, "Bridge dynamic responses due to road surface roughness and braking of vehicle," Journal of Sound and Vibration, vol. 282, no. 3-5, pp. 805-830, 2005.

[4] H. Li, J. Wekezer, and L. Kwasniewski, "Dynamic response of a highway bridge subjected to moving vehicles," Journal of Bridge Engineering, vol. 13, no. 5, pp. 439-448, 2008.

[5] Y. L. Xu and W. H. Guo, "Dynamic analysis of coupled road vehicle and cable-stayed bridge systems under turbulent wind," Journal of Engineering Structures, vol. 25, no. 4, pp. 473-486, 2003.

[6] C. S. Cai and S. R. Chen, "Framework of vehicle-bridge-wind dynamic analysis," Journal of Wind Engineering and Industrial Aerodynamics, vol. 92, no. 7-8, pp. 579-607, 2004.

[7] F. T. K. Au, P. Lou, J. Li, and R. J. Jiang, "Simulation of vibration of Ting-Kau Bridge due to vehicular loading," in Proceedings of the Conference of Environmental Vibrations: Prediction, Monitoring, Mitigation and Evaluation, pp. 1109-1116, 2009. 
[8] Y. Zhou, W. Bao, H. Zhai, and Y. Liu, "Study of standard fatigue design load for steel highway bridges," China Civil Engineering Journal, vol. 43, no. 11, pp. 79-85, 2010.

[9] J. M. Biggs, Introduction to Structure Dynamics, McGraw-Hill, New York, NY, USA, 1964.

[10] J.-W. Li, H.-J. Zhang, and W.-S. Han, "Wind-induced response of cable-stayed bridge with consideration of reynolds number effect," China Journal of Highway and Transport, vol. 22, no. 2, pp. 42-47, 2009.

[11] F. Y. Xu, X. Z. Chen, C. S. Cai, and A. R. Chen, "Determination of 18 flutter derivatives of bridge decks by an improved stochastic search algorithm," Journal of Bridge Engineering, vol. 17, no. 4, pp. 576-588, 2012.

[12] C. J. Dodds and J. D. Robson, "The description of road surface roughness," Journal of Sound and Vibration, vol. 31, no. 2, pp. 175-183, 1973.

[13] J. Sukhvarsh and G. Sanjay, "Road surface roughness generation by power spectral density in bridge design," in Proceedings of the ASCE Structures Congress, 2008.

[14] G. Deodatis, "Simulation of ergodic multivariate stochastic processes," Journal of Engineering Mechanics, vol. 122, no. 8, pp. 778-787, 1996.

[15] Y. Li, S. Qiang, H. Liao, and Y. L. Xu, "Dynamics of windrail vehicle-bridge systems," Journal of Wind Engineering and Industrial Aerodynamics, vol. 93, no. 6, pp. 483-507, 2005.

[16] American Association of State Highway and Transportation Officials, Standard Specifications for Highway Bridges, AASHTO, Washington, D.C., USA, 1996.

[17] Ministry of Communications, General Code for Design of Highway Bridges and Culverts, China Communications Press, Beijing, China, 2004.

[18] Ministry of Transport and Communications, Ontario Highway Bridge Design Code, Highway Engineering Division, Ontario, Canada, 1983. 

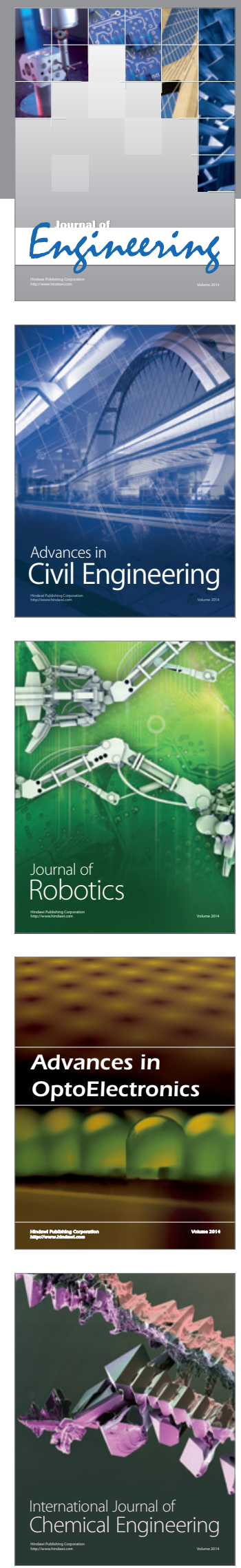

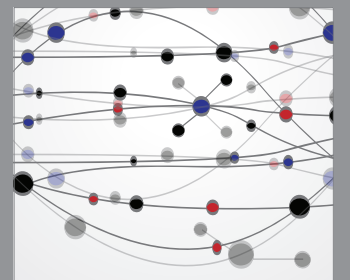

The Scientific World Journal
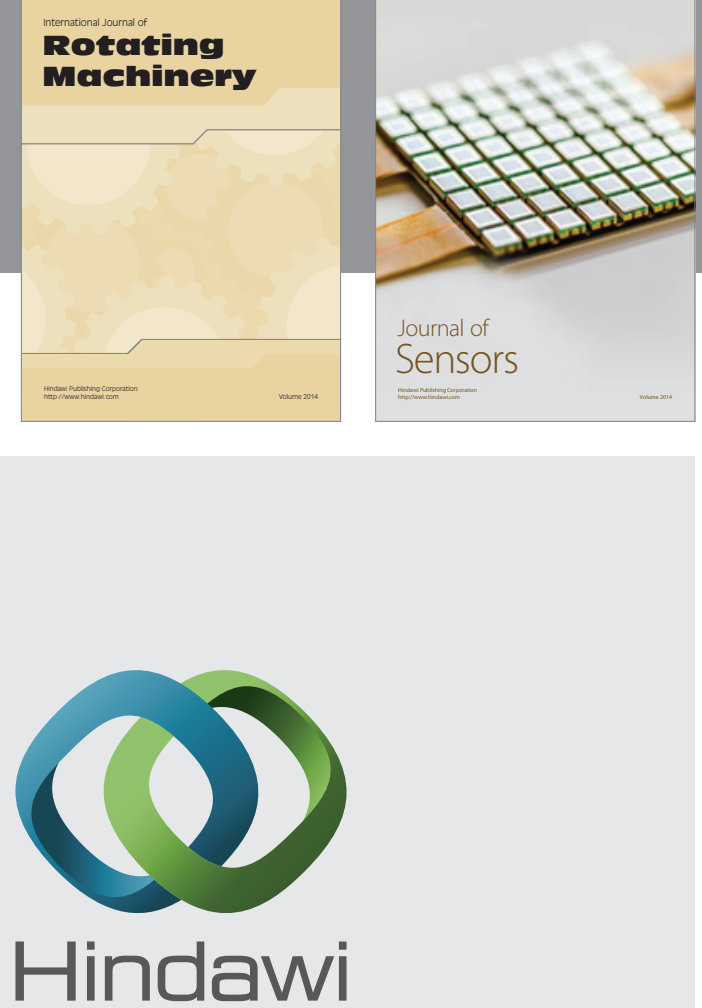

Submit your manuscripts at http://www.hindawi.com
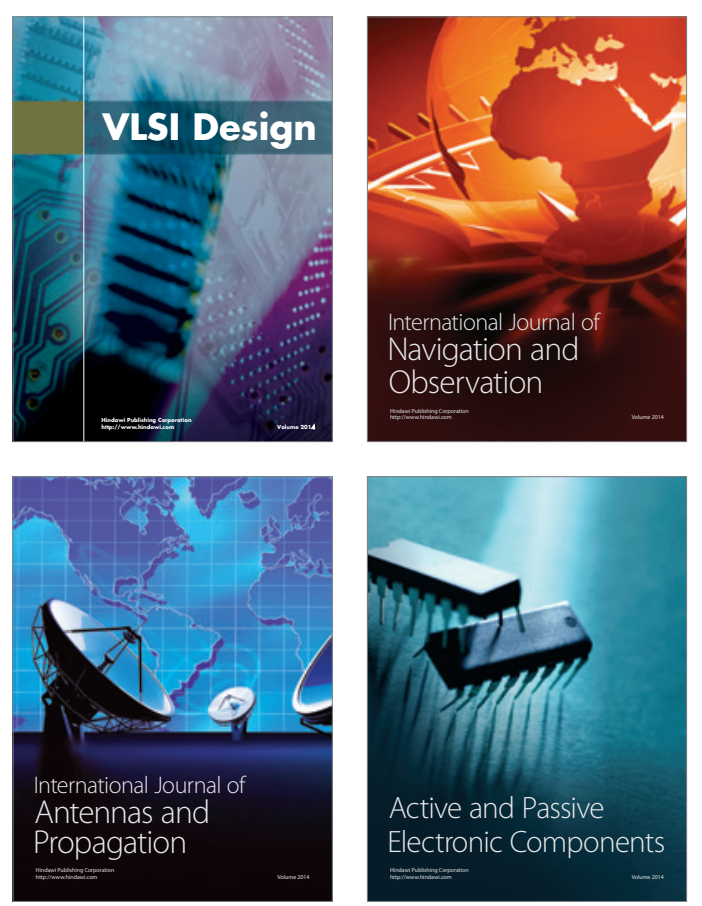
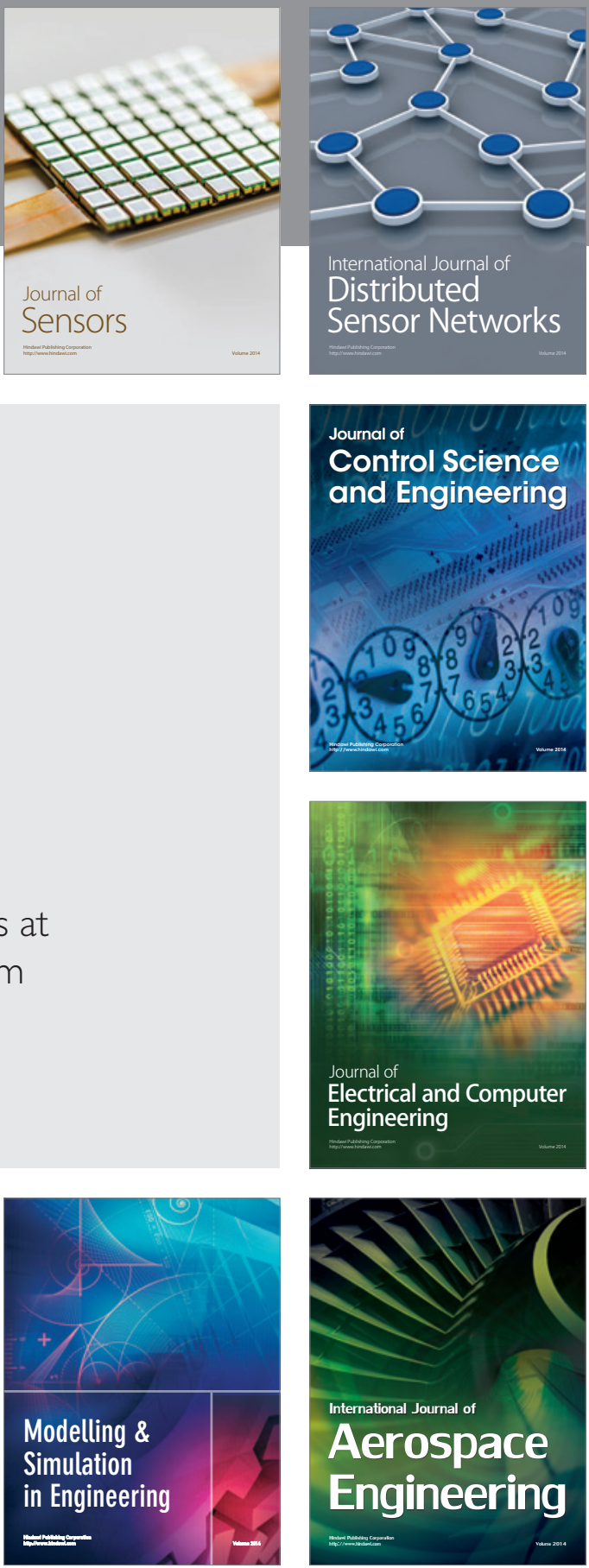

Journal of

Control Science

and Engineering
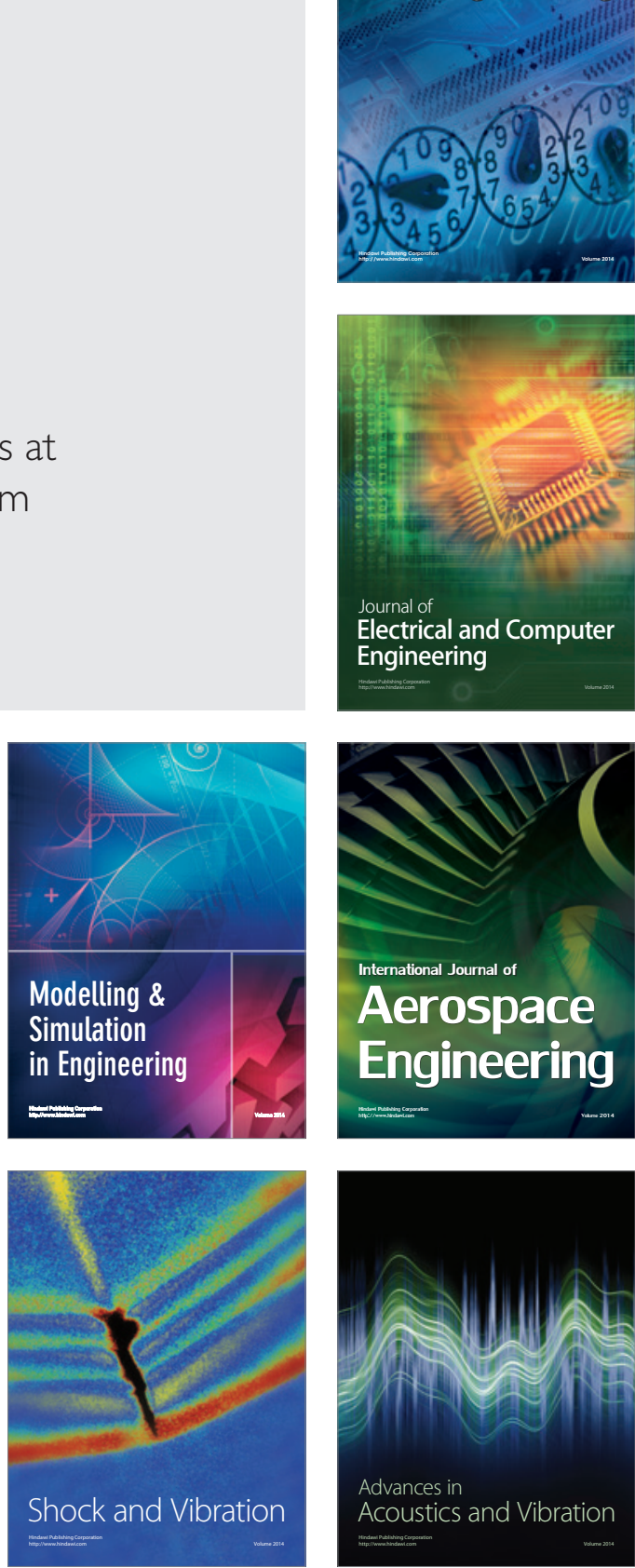